\title{
Adipocyte Specific HO-1 Gene Therapy Is Effective in Antioxidant Treatment of Insulin Resistance and Vascular Function in an Obese Mice Model
}

\author{
Shailendra P. Singh ${ }^{1}$, Menachem Greenberg ${ }^{1}$, Yosef Glick ${ }^{1}$, Lars Bellner ${ }^{1}$, Gaia Favero ${ }^{2}{ }^{\mathbb{D}}$, \\ Rita Rezzani ${ }^{2,3}$ (D), Luigi Fabrizio Rodella 2,3, Kevin Agostinucci ${ }^{1}$, Joseph I. Shapiro ${ }^{4}$ and \\ Nader G. Abraham 1,4,* \\ 1 Departments of Medicine and Pharmacology, New York Medical College, Valhalla, NY 10595, USA; \\ spbiotech2004@gmail.com (S.P.S.); mgreenbe20@nymc.edu (M.G.); yglick2@nymc.edu (Y.G.); \\ Lars_Bellner@nymc.edu (L.B.); kagostin@student.nymc.edu (K.A.) \\ 2 Anatomy and Physiopathology Division, Department of Clinical and Experimental Sciences, University of \\ Brescia, 25123 Brescia, Italy; gaia.favero@med.unibs.it (G.F.); rezzani@med.unibs.it (R.R.); \\ rodella@med.unibs.it (L.F.R.) \\ 3 Interdepartmental University Center of Research "Adaption and Regeneration of Tissues and \\ Organs-(ARTO)", University of Brescia, 25123 Brescia, Italy \\ 4 Departments of Cardiology and Internal Medicine, Joan C. Edwards School of Medicine, Marshall \\ University, Huntington, WV 25701, USA; ShapiroJ@marshall.edu \\ * Correspondence: nader_abraham@nymc.edu; Tel.: +914-594-3121
}

Received: 6 November 2019; Accepted: 30 December 2019; Published: 1 January 2020

\begin{abstract}
Obesity is a risk factor for vascular dysfunction and insulin resistance. The study aim was to demonstrate that adipocyte-specific HO-1 (heme oxygenase-1) gene therapy is a therapeutic approach for preventing the development of obesity-induced metabolic disease in an obese-mice model. Specific expression of HO-1 in adipose tissue was achieved by using a lentiviral vector expressing HO-1 under the control of the adiponectin vector (Lnv-adipo-HO-1). Mice fed a high-fat diet (HFD) developed adipocyte hypertrophy, fibrosis, decreased mitochondrial respiration, increased levels of inflammatory adipokines, insulin resistance, vascular dysfunction, and impaired heart mitochondrial signaling. These detrimental effects were prevented by the selective expression of $\mathrm{HO}-1$ in adipocytes. Lnv-adipo-HO-1-transfected mice on a HFD display increased cellular respiration, increased oxygen consumption, increased mitochondrial function, and decreased adipocyte size. Moreover, RNA arrays confirmed that targeting adipocytes with HO-1 overrides the genetic susceptibility of adiposopathy and correlated with restoration of the expression of anti-inflammatory, thermogenic, and mitochondrial genes. Our data demonstrate that HO-1 gene therapy improved adipose tissue function and had positive impact on distal organs, suggesting that specific targeting of HO- 1 gene therapy is an attractive therapeutic approach for improving insulin sensitivity, metabolic activity, and vascular function in obesity.
\end{abstract}

Keywords: antioxidant; gene-HO-1; adiponectin; adipocytes; PGC1- $\alpha$; hyperglycemia; hypertension

\section{Introduction}

Obesity has become highly prevalent in the past decade worldwide, affecting all age groups and populations [1-3]. It is estimated that approximately $35 \%$ of the general population in high-income countries are overweight, and $30 \%$ are obese [2]. Obesity is a risk factor for type 2 diabetes, coronary heart disease, chronic kidney disease, hypertension, and high cholesterol levels [3]. In the United States, approximately $70 \%$ of adults and $32 \%$ of children are currently either overweight or obese, 
and the percent of obese patients continues to rise every year [4]. Obesity is associated with inflammation of the heart, often leading to myocardial infarction, reduction in left ventricular function, and reduced ejection fraction [5,6]. White fat, whether epicardial or visceral, is considered a major source of inflammation [7-9] and leads to a reduction in mitochondrial thermogenesis and biogenesis signaling [10-12].

In addition to increasing ectopic fat around the heart, obesity leads to insulin resistance in humans [13]. Visceral fat and insulin resistance are related to metabolic disease, as a result of a decrease of HO-1 show elevation of reactive oxygen species (ROS) [14-18] and diminished levels of the antioxidant gene heme oxygenase-1 (HO-1). Low levels of visceral adipose tissues HO- 1 are correlated with increased hip-to-waist ratio and insulin resistance [19]. Importantly, reduced levels of HO-1 are associated with reduced antioxidative properties and insulin resistance associated with obesity [11,20,21]. In fact, humans and mice lacking HO-1 suffer from severe organ damage due to major increases in ROS [14-18]. ROS plays a major role in reprogramming a normal adipocyte phenotype to inflamed adipocytes, resulting in adiposopathy [22-24]. Affected adipocytes proceed to terminal differentiation and inflammation, resulting in adipocyte dysfunction [23,25]. Obese animal models have low levels of HO-1 and are therefore more susceptible to oxidative stress and cytotoxicity caused by a build-up of heme, a pro-oxidant, and ROS [1,24,26].

$\mathrm{HO}-1$ is the inducible isoform (HO-2 is the constitutive form) which plays a central role in maintaining beige-like adipose tissue and improves cardiovascular and liver function [27,28]. Hence, pharmacological agents that upregulate HO-1 expression have been used as a therapeutic approach for the treatment of obesity and its associated metabolic and cardiovascular diseases [27,29]. However, these interventions are not specific to adipose tissue in prevention of the inflammatory adipokines. As we and others have previously shown, lentiviruses vectors are capable of persistent transgene expression for one year in treatment of hypertension and obesity [30]. The aim of the present studies was to selectively target adipose tissue, specifically utilizing an adiponectin promoter with lentivirus for the delivery of $\mathrm{HO}-1$ in growing adipose tissue, in order to reprogram the white fat to beige-like fat and decrease inflammatory adipokines. The hypothesis was that expression of HO-1, specifically to the adipocyte, would have a beneficial impact on obesity and obesity-related pathologies. Here, we demonstrated for the first time that the injection of a lentiviral-adiponectin promoter encoding HO-1 resulted in a long-lasting effect, which prevented the obesity-mediated increase of inflammation, fibrosis, and insulin resistance in HFD-fed mice. These results underscore the potential of antioxidant (HO-1) gene therapy in the treatment of obesity-derived metabolic diseases.

\section{Materials and Methods}

\subsection{Animal Experimentation and Generation of Lentiviral Vector-Mediated HO-1 Overexpressing Mice}

All animal experiments followed a protocol approved by the New York Medical College (IACUC) institutionally approved protocol, in accordance with NIH Guidelines. Six-week-old male C57BL/6J background mice, were purchased from Jackson Labs (Bar Harbor, ME, USA). For experiments, animals were divided into 3 groups (6 mice per group): lean, HFD, and HFD + Lnv-adipo-HO-1. Lean mice were fed a normal chow diet, while C57 mice were fed an HFD for 23 weeks, as previously described [31,32]. Lentiviral vectors under adiponectin-specific promoter expressing either human HO-1 or GFP adipocyte adiponectin-specific promoter were constructed by using the LentiMax ${ }^{\mathrm{TM}}$ system (Lentigen, Baltimore, MA, USA and Vector Builder, Shenandoah, TX 77384, USA). The adipose tissues were targeted by 2 bolus injections into the retro orbital vein of lentiviral constructs expressing $\mathrm{HO}-1$, under the control of the adiponectin promoter (Lnv-adipo-HO-1). The first injection of Lnv-adipo-HO-1 (50 $\mu \mathrm{L}, 1 \times 10^{9}$ $\mathrm{TU} / \mathrm{mL}$ in saline) at the 10 th week and second injection into retro orbital vein $\left(75 \mu \mathrm{L} 1 \times 10^{9} \mathrm{TU} / \mathrm{mL}\right.$ in saline) at the 11th week were administered into HFD mice, while untreated HFD mice were similarly injected with Lnv-adipo-GFP vector injection control fat. Lean animals (group 1) were injected with mock virus (placebo), as previously described [33]. 


\subsection{Generation of Lentiviral Vector-Mediated HO-1 Overexpressed and Deficient Adipocyte Cells for In Vitro Study}

Adipo-ORF HO-1 lentivirus and Adipo-sh HO-1 (Vector builder, Shenandoah, TX 77384, USA) were applied to mice-derived adipocyte (3T3-L1) cells, as previously described [33,34] for adipocyte (3T3-L1). One million cells were seeded in 6-well plates in transducer medium that contained $1 \times 10^{6}$ transducing units (TU) of lentiviral particles, for $3 \mathrm{~h}$, to maximize the contact of lentiviral particles. Control 3T3-L1 cells were treated with the transduction medium. Cells that overexpression HO-1 or HO-1 deficient treated with $10 \mu \mathrm{g} / \mathrm{mL}$ puromycin. Adipo-ORF-HO-1 lentivirus and adipo-Sh-HO-1 clone were cultured. A similar procedure was used to isolate TWIST silencing, as previously described $[10,35,36]$.

\subsection{Measurement of Mitochondrial Oxygen-Consumption Rate in Adipocytes}

The oxygen consumption rate (OCR) was measured by using an extracellular flux analyzer XFp (Seahorse Bioscience, Houston, TX, USA). Mice-derived 3T3-L1 adipocyte cells were plated at $4 \times 10^{5}$ cells/well in a Seahorse 8-well microplate in DMEM growth media [12,34]. The medium was removed and incubated in XF assay, and after 32 min of measuring the basal respiration, oligomycin $(2.5 \mu \mathrm{M})$ was injected. After $50 \mathrm{~min}$, cells were treated with the uncoupling carboxyl-cyanide p-trifluoromethoxy phenyl hydrazine, into each well (FCCP) $(1 \mu \mathrm{M})$, and at $74 \mathrm{~min}$, rotenone $(2.5 \mu \mathrm{M})$ was added to induce maximum respiration (uncoupled respiration), and it was followed by antimycin A, an inhibitor of ATP to decrease OCR $(2.5 \mu \mathrm{M})$, at $98 \mathrm{~min}$. ATP turnover and OCR were determined after the treatment with oligomycin and FCCP. OCR values normalized against total proteins.

PCR arrays, using the $\mathrm{RT}^{2}$ Profiler ${ }^{\mathrm{TM}}$ PCR Array Mouse Adipogenesis (Qiagen, Germantown, MD, USA, product no. 330231 and Cat. No. PAMM-049Z), were performed by following the manufacturers' protocols. Gene-expression levels were compared to housekeeping as previously described using heatmap [6]. These genes are known to encoding pre-adipocyte cell markers, proliferation, differentiation and adipogenesis, lipid metabolism, and obesity [6].

Gene expression in which $\log 10$ transformed mean values lean $(n=3)$ relative to the mean values $(n=3)$ expressed in HF-mice and HF-Lnv-adipo-HO-1-lentiviral subgroups [6]. Details of this method, including Pearson correlation, are well described [6,37] at https://CRAN.R-project.org/package=gplots, and https://www.R-project.org/.

\subsection{RNA, RT-PCR, Western Blot Analysis, Histology, and Adipocyte Cell-Size Measurements}

Frozen mouse tissues, liver, kidney heart, and adipose tissue, were ground under liquid nitrogen and suspended in homogenization buffer, as previously described. Cells were lysed with lysis buffer supplemented with protease and phosphatase inhibitors. RNA, PCR, and immunoblotting for HO-1, SIRT1, MFN2, Fis1, OPA1, COX1, COX2, UCP1, TFAM, aP2, Twist1, NOV, ACC, PEG1/MEST, MnSOD, AMPK, pAMPK, AKT, and pAKT, and PGC- $1 \alpha$ and phosphorylation of insulin receptors (IR) IRp972, IRp1146, adiponectin, $\beta$-actin, and GAPDH, were performed, as described $[11,30,34,38]$.

\subsection{Measurements of Oxygen Consumption, Fasting Blood Glucose, and Blood Pressure}

Oxygen consumption in treated mice placed in an oxylet chamber and hourly respiratory quotients were calculated based on the $\mathrm{VCO}_{2}$ and $\mathrm{VO}_{2}$. Individual readings were recorded twice per mouse, as previously described [38]. Fasting blood glucose and blood pressure was measured by using standard tail-cuff method, as described [21,30]. 


\subsection{Assessment of Vasorelaxation in Renal Interlobar Artery Rings (Myograph)}

Renal interlobar arteries were cut into ring segments ( $2 \mathrm{~mm}$ in length). Vessels were contracted with phenylephrine $\left(10^{-6} \mathrm{M}\right)$, and vasorelaxation responses to cumulative increments in Acetylcholine $\left(10^{-8}\right.$ to $\left.10^{-4} \mathrm{~mol} / \mathrm{L}\right)$ concentrations were examined, as previously described [39]

\subsection{Statistical Analysis}

Data is expressed as mean \pm SEM. Student's $t$-test and one-way ANOVA with Bonferroni's comparison were used; the null hypothesis was rejected at $p<0.05$, and data are plotted [11,21,30].

\section{Results}

3.1. Lnv-adipo-HO-1 Administration Mediated Induction of HO-1 Expression Only in Adipose Tissue and Rescued HFD-Induced Phenotype and Fibrosis in Mice

Basal level of HO-1 mRNA expression in visceral adipose was similar to that of kidney and heart. After Lnv-adipo-HO-1 treatment HO-1 mRNA levels in visceral adipose tissue increased approximately three-fold, as compared to control $(p<0.05)$, while it was unchanged in the kidney and heart (Figure 1A).

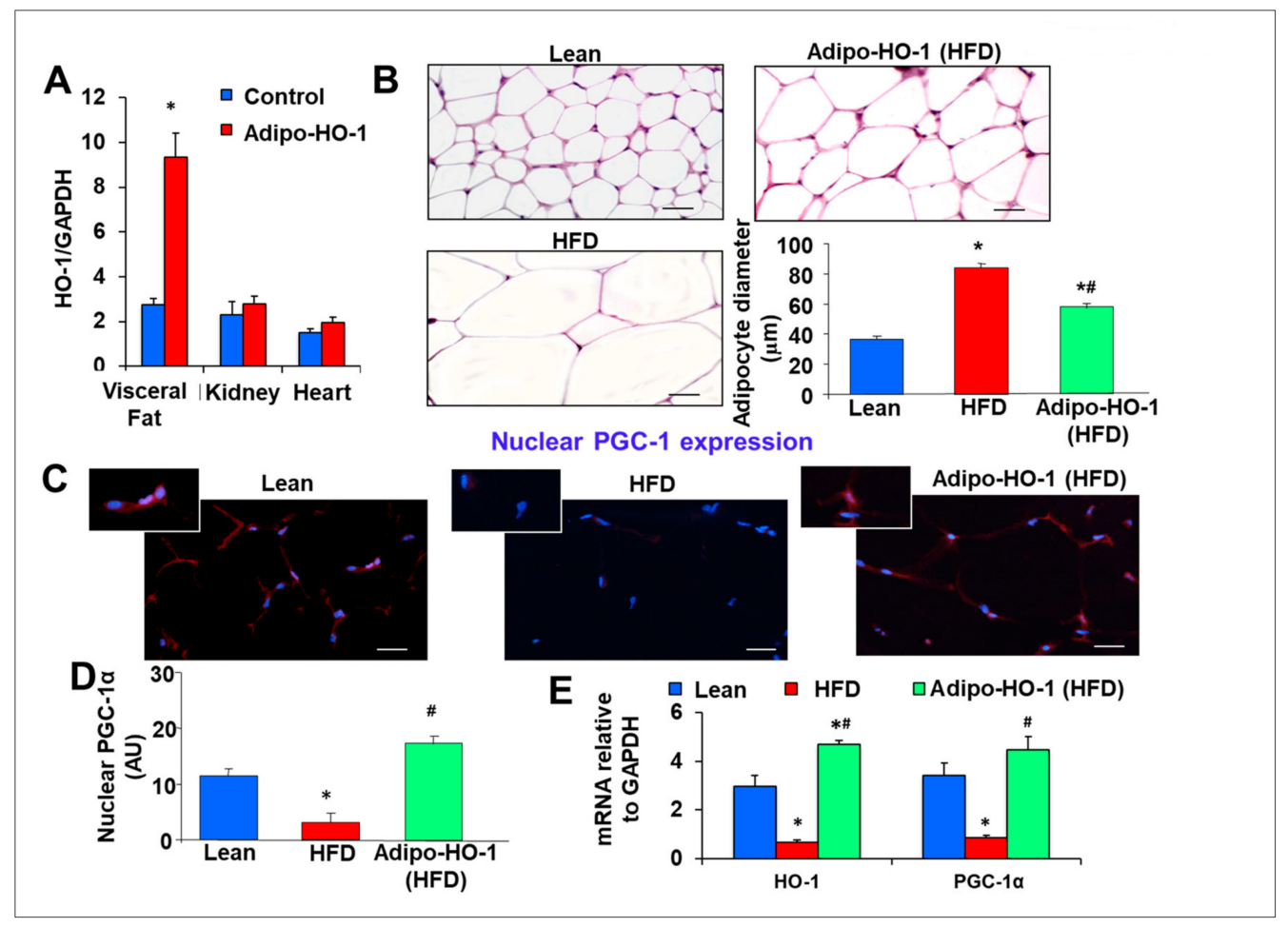

Figure 1. Cont. 

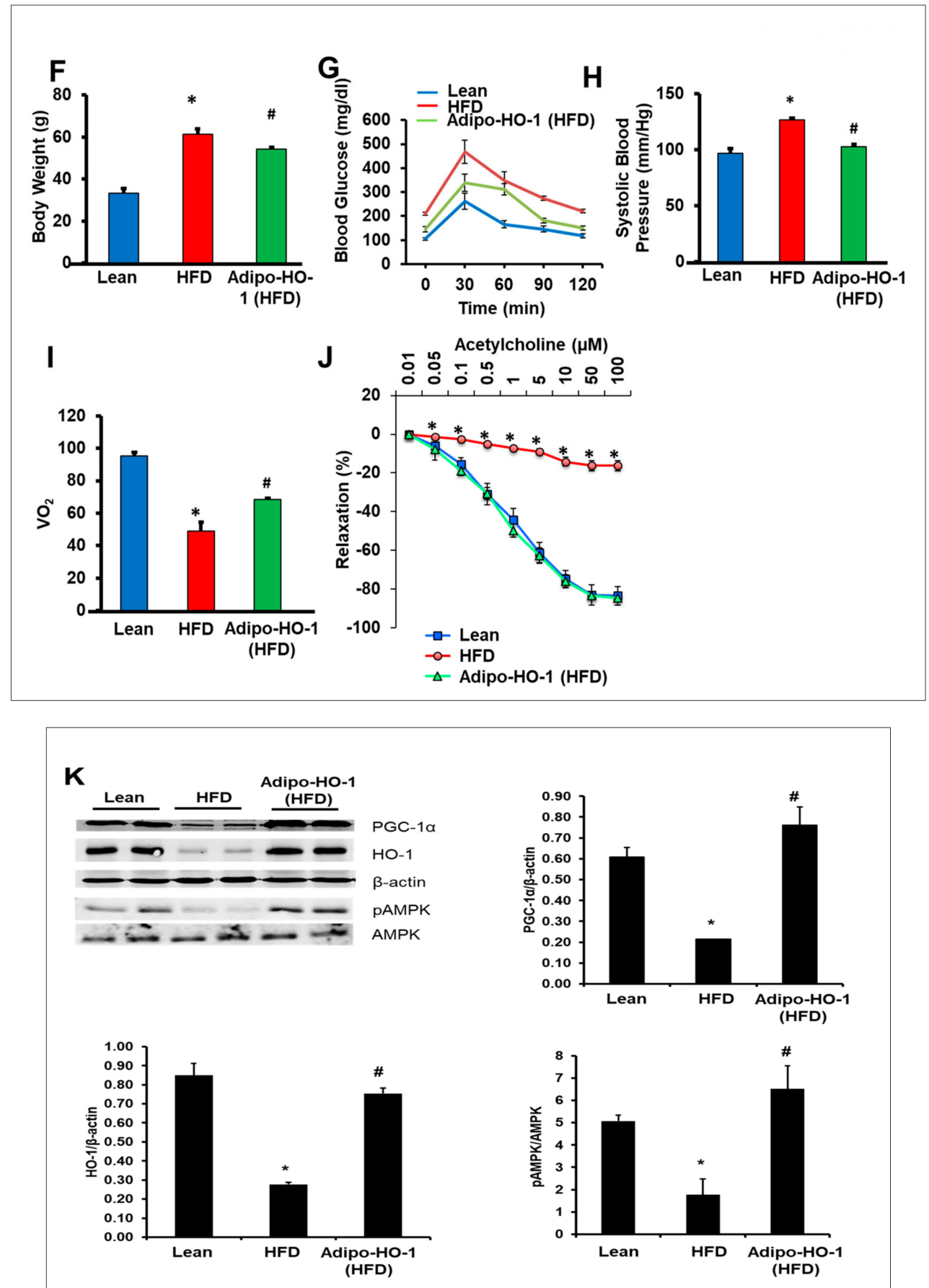

Figure 1. Effects of adipocyte-specific overexpression of HO-1 (heme oxygenase-1) in high-fat diet (HFD)-fed mice. (A) HO-1 mRNA expression levels in visceral fat $* p<0.05$ vs. control, kidney and heart in Lnv-adipo-HO-1, $n=5$. Comparisons of adipose tissues of lean, HFD-fed, and Lnv-adipo-HO-1 (HFD)-fed mice: (B) histological analysis of adipocyte diameter, using hematoxylin-eosin and Masson-trichrome staining; (C) immunofluorescence photomicrographs of PGC-1 $\alpha$ expression (red staining), scale bar $20 \mu \mathrm{m}(10 \times)$. (D) Immunomorphometrical measurement of nuclear localization of PGC-1 (AU); (E) mRNA levels of HO-1 and PGC-1 $\alpha$. (F) Body weight (BW); (G) fasting glucose (at 10) and glucose tolerance test; (H) Systolic blood pressure; (I) oxygen consumption (VO2); (J) acetylcholine-mediated relaxation of renal interlobar arteries $n=5,{ }^{*} p<0.05$ vs. lean, $\# p<0.05$ versus fat. (K) Representative Western blot analysis of PGC- $1 \alpha, \mathrm{HO}-1, \mathrm{pAMPK}$, and AMPK in heart-tissue lysates of lean, HFD-fed, and Lnv-adipo-HO-1 HFD-fed mice; $n=5,{ }^{*} p<0.05$ versus lean; \# $p<0.05$ versus HFD alone. 
Hematoxylin-eosin and Masson trichrome staining of adipose tissue of lean, HFD-fed control, and Lnv-adipo-HO-1-injected mice revealed an increase $\left({ }^{*} p<0.05\right)$ in adipocyte size (hypertrophy) in HFD-fed mice as compared to lean mice (Figure 1B). Adipocyte hypertrophy was reversed by administration of Lnv-adipo-HO-1 (\# $p<0.05$ vs. control HFD-fed mice, Figure 1B). We previously described that injection of HFD-fed obese mice with Lnv-adipo-GFP does not affect adipocyte size, as compared to control obese HFD-fed mice.

\subsection{HO-1 Mediated Co-Localization of PGC-1 $\alpha$ : A Portion of PGC-1 $\alpha$ Localized to the Nucleus in Adipose Tissue}

For PGC- $1 \alpha$ to act as a transcriptional co-activator it must be present in the nucleus. Figure 1C,D shows, by immunofluorescence staining (red (PGC-1 $\alpha$ ), blue (DAPI nuclei)) and arbitrary units, respectively, the subcellular localization of PGC- $1 \alpha$. Adipocytes from HFD-fed control mice showed reduced $(* p<0.05)$ nuclear localization of PGC- $1 \alpha$, as compared to lean mice. Importantly, Lnv-adipo-HO-1-transduced mice fed HFD showed a significant increase $(\# p<0.05)$ in PGC-1 $\alpha$ nuclear localization (Figure 1C,D). Moreover, both HO-1 and PGC- $1 \alpha$ mRNA levels in adipose tissue (Figure 1E) were reduced $(* p<0.05)$ in mice fed an HFD, as compared to adipose tissues of lean mice. Increased HO-1 expression in adipose tissue of HFD-fed mice led to a normalization of adipose tissue PGC- $1 \alpha$ mRNA levels (\# $p<0.05$ vs. untreated HFD-fed mice) (Figure 1E). As expected, the adipose tissue mRNA levels of HO-1 are significantly elevated in HO-1 overexpressing mice, as compared to both lean $\left({ }^{*} p<0.05\right)$ and control HFD-fed mice $(\# p<0.05)$ (Figure 1E).

\subsection{Lnv-adipo-HO-1 Induction Decreased Weight Gain, Normalized Fasting Blood Glucose, Glucose Intolerance, Systolic Blood Pressure, and Oxygen Consumption}

HFD-fed mice exhibited an average body weight gain of $2 \mathrm{~g} /$ week (data not shown), with an average final weight of $61.5 \pm 2.4 \mathrm{~g}$, significantly higher than lean mice $(33.2 \pm 2.1 \mathrm{~g})\left({ }^{*} p<0.05\right)$ (Figure 1G). Lnv-adipo-HO-1 decreased the final body weight $(54.1 \pm 1.1 \mathrm{~g}$ ) by an average of $7.4 \mathrm{~g}$ (\# $p$ $<0.05)$, as compared to untreated HFD-fed mice. Fasting blood glucose levels in lean, HFD-fed, and Lnv-adipo-HO-1-treated HFD-fed mice were $105 \pm 11.8,210 \pm 14.1$, and $145.5 \pm 1.2 \mathrm{mg} / \mathrm{dL}$, respectively (Figure 1I, Time 0). Lnv-adipo-HO-1 reduced the effects of an HFD on fasting blood glucose levels. Lnv-adipo-HO-1 treatment increased the tolerance to glucose challenge $(p<0.05)$ compared with control HFD-fed mice (Figure 1I). Systolic blood pressure was increased in HFD-fed mice compared to lean mice. Importantly, Lnv-adipo-HO-1 decreased blood pressure $(\# p<0.01)$ in mice compared with control HFD-fed mice (Figure 1F).

We examined the effect of Lnv-adipo-HO-1 on mice fed an HFD on both $\mathrm{O}_{2}$ consumption and the ratio of $\mathrm{CO}_{2} / \mathrm{O}_{2}$. As expected, mice on an HFD displayed a significant $(p<0.05)$ decrease in $\mathrm{VO}_{2}$ consumption compared to lean mice. (Figure 1H). However, HFD-fed mice treated with Lnv-adipo-HO-1 exhibited a significant $(p<0.05)$ increase in oxygen consumption, with a concomitant lowering of $\mathrm{VCO}_{2} / \mathrm{VO}_{2}$. As seen in Figure 1J, vascular function, measured as the relaxation in response to acetylcholine, was severely impaired in renal interlobar arteries of mice fed an HFD in which group the vessels' maximal relaxation was less than $20 \%$ at $10^{-4} \mathrm{M}$ acetylcholine, as compared to vessels isolated from kidneys of lean mice with a maximal relaxation of about $80 \%$ at $10^{-4} \mathrm{M}$ acetylcholine. The maximal relaxation of vessels in the Lnv-adipo-HO-1 injected mice on HFD was not significantly different from the vessels of lean mice (Figure 1J). That the Lnv-adipo-HO-1 mice restored maximal relaxation to acetylcholine to levels no different from those recorded in lean mice strengthens our finding that adipocyte-specific expression of HO-1 prevents the impairment of vascular reactivity in renal arteries of obese mice.

The effect of Lnv-adipo-HO-1 in adipose tissues extended to distal organs, including cardiac tissue. This is demonstrated by increased targeting of adipose tissue with HO-1, resulting in the restoration of cardiac HO-1, PGC1, and pAMPK, as compared to lean mice. More importantly, targeting adipose tissue with Lnv-adipo-HO-1 increased $(p<0.05)$ PGC- $1 \alpha$ and pAMPK in obese mice (Figure 1K). 
3.4. Lnv-adipo-HO-1 Treatment Mediated Induction of HO-1, Sirt1, PGC-1 $\alpha$, PRDM16, UCP1, Adiponectin, and $\mathrm{MnSOD}$

Our study demonstrated reduction in HO-1 protein expression in adipose tissue of HFD-fed mice compared to control lean mice $(p<0.05)$. As seen in Figure 2, Western blot analysis demonstrated significant $(p<0.05)$ upregulation of HO-1 protein after Lenti-adipo-HO1 treatment in adipose tissue of HFD-fed mice (Figure 2). While Sirt1 and PGC-1 $\alpha$ expression was reduced in mice adipose tissues of HFD-fed mice as compared to levels in adipose tissues of lean mice, the levels of both Sirt1 and PGC-1 $\alpha$ were normalized in adipose tissue of HFD-fed mice and Lnv-adipo-HO-1-treated mice (Figure 2).

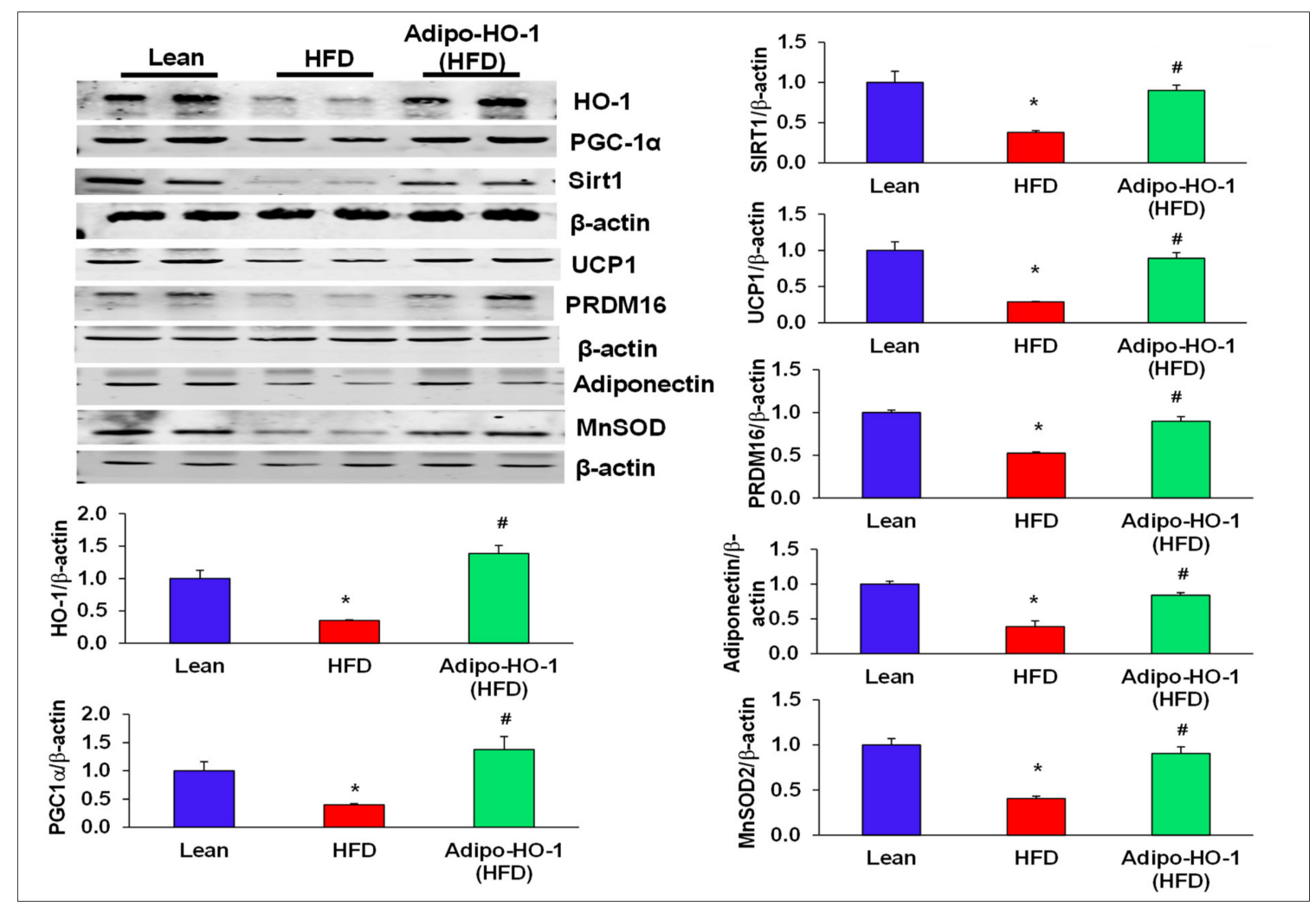

Figure 2. Lnv-adipo-HO-1 treatment mediated induction of key proteins involved in adipocyte metabolism. Representative Western blot analysis of HO-1, PGC-1 $\alpha$, Sirt1, MnSOD, PRDM16, UCP-1, and MnSOD with their corresponding $\beta$-actin in adipose tissue of lean, HFD, and Lnv-adipo-HO-1 (HFD) mice; $n=5,{ }^{*} p<0.05$ versus lean; $\# p<0.05$ versus HFD alone.

Uncoupling protein $1(\mathrm{UCP} 1)$ was upregulated $(p<0.05)$ in adipose tissues of mice treated with Lenti-adipo-HO1 (Figure 2). We examined the effect of HFD on the brown-fat-specific gene, PRMD16, and found that PRMD16 protein expression levels were decreased $(p<0.05)$ in adipose tissue of HFD-fed control mice, an effect that was normalized in adipose tissue of Lenti-adipo-HO1 mice (Figure 2). Furthermore, Lnv-adipo-HO-1 treated mice expressed higher $(p<0.05)$ levels of MnSOD and adiponectin protein expression compared with HFD-fed mice (Figure 2).

3.5. Effect of Lnv-adipo-HO-1 Mitochondrial Mfn2, OPA-1, FIS-1, COX1, and COX2 Levels in Adipose Tissue of High-Fat-Diet-Fed Mice

The levels of the mitochondrial fusion-associated proteins MFN2 and OPA1, in visceral adipose tissue of mice fed an HFD were significantly $(p<0.05)$ reduced as compared to lean mice fed regular chow (Figure 3). The levels of these proteins were normalized in HFD mice treated with Lnv-adipo-HO-1, an effect that was dependent on HO-1. Conversely, Western blot results demonstrated increased levels of mito-fission related Fis1 in adipose tissue of control HFD-fed mice (Figure 3) an 
effect of obesity that was completely prevented in adipose tissue of the Lnv-adipo-HO-1 mice fed an HFD (Figure 3). Moreover, expression of COX-I and II proteins was decreased in HFD-fed mice ( $p<$ 0.05), an effect that was reversed in Lnv-adipo-HO-1-treated mice adipose tissue (Figure 3).

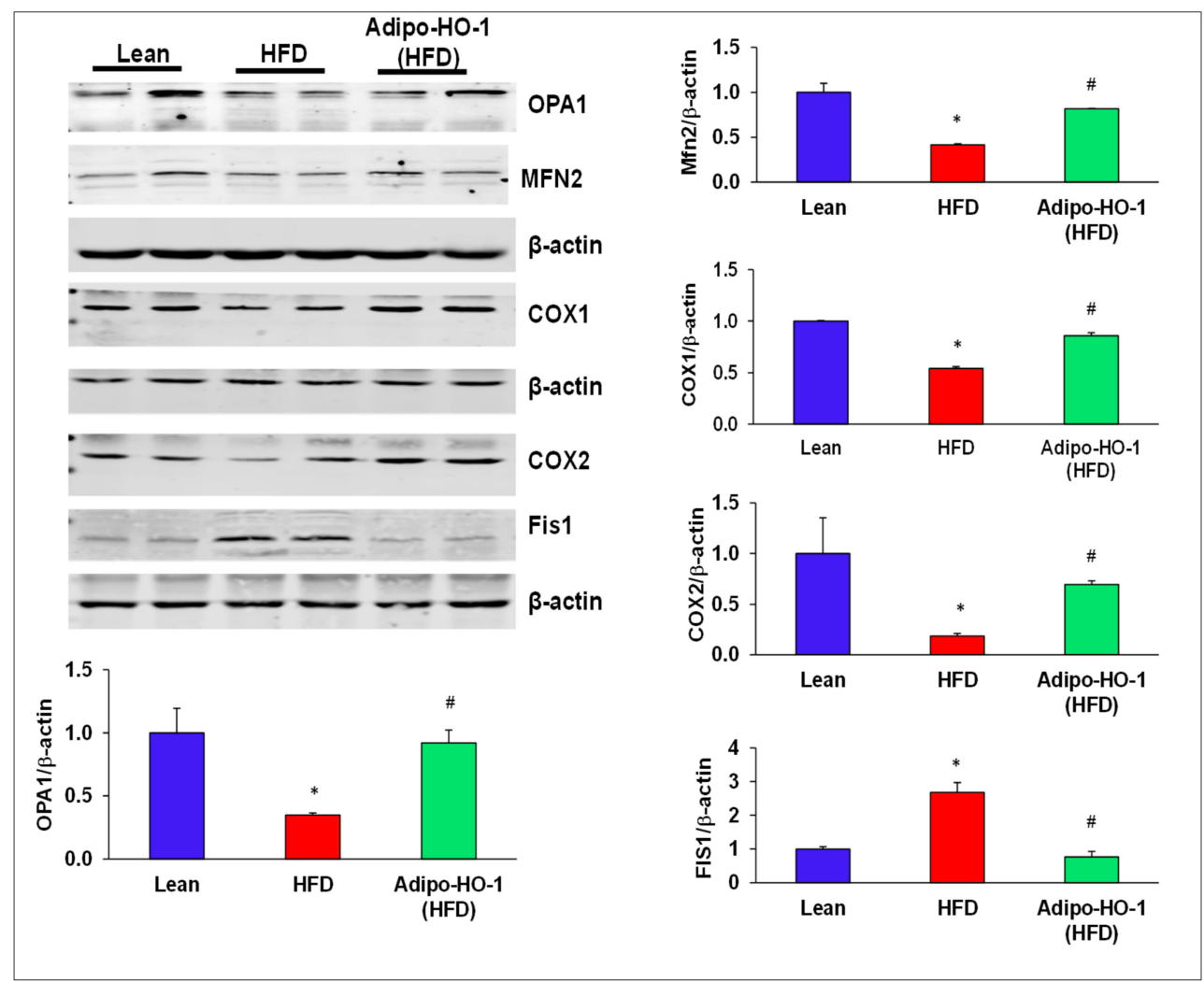

Figure 3. Effect of Lnv-adipo-HO-1 of key mitochondrial protein levels in adipose tissues of Lnv-adipo-HO-1 (HFD) mice. Representative Western blot analysis of OPA1, MFN2, COX1, COX2, and Fis1 in adipose tissue of lean, HF, and Lnv-adipo-HO-1 (HFD) mice; $n=5,{ }^{*} p<0.05$ versus lean; \# $p<$ 0.05 versus HFD alone.

3.6. Lnv-adipo-HO-1 Administration on Expression of Adipogenic and Inflammatory Mediators in Adipose Tissue of Obese Mice

Aberrant expression of nephroblastoma overexpressed (NOV) and Twist1 are evident in inflammation and obesity. As seen in Figure 4, Twist1 and NOV protein expression in adipose tissue of Lnv-adipo-HO1-treated mice was reduced $(p<0.05)$ as compared with HFD-fed mice adipose tissue (Figure 4). Moreover, Western blot analysis demonstrated increased expression of adipocyte protein 2 (ap2) and mesoderm-specific transcript (Mest) protein expression in adipose tissue of HFD-fed mice, as compared to levels in adipose tissues of lean mice. HFD-fed mice treated with Lnv-adipo-HO-1 had significantly $(p<0.05)$ diminished protein expression of both MEST and ap2 in adipose tissue compared with control HFD-fed mice (Figure 4). As shown in Figure 5, mRNA levels of TNF- $\alpha$, IL1 $\beta$, CCL2, and NOV in HFD-fed mice were increased $(p<0.05)$ compared with lean mice. The expression of these genes was reduced $(p<0.05)$ in adipose tissues of Lnv-adipo-HO1-HFD-fed mice. Moreover, HFD-fed mice displayed an increase $(p<0.05)$ in adipose tissue fibrosis compared to lean mice, an effect of HFD that was reduced $(p<0.05)$ in Lnv-adipo-HO-1-injected HFD-fed mice (Figure 5). 


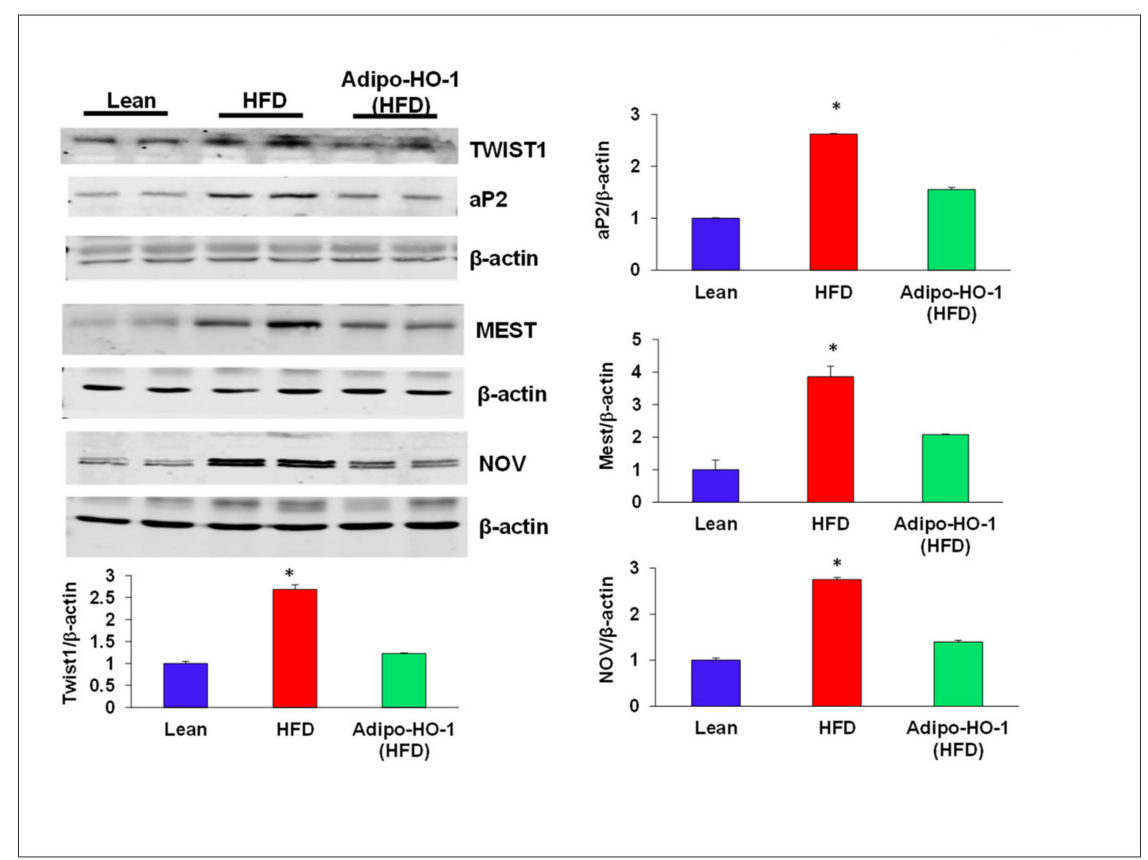

Figure 4. Expression of adipogenic and inflammatory mediators in adipose tissue of lean, HFD, and Lnv-adipo-HO-1 (HFD) mice. Representative Western blot analysis of TWIST1, aP2, MEST, and NOV and their respective $\beta$-actin in adipose tissue of lean, HFD, and Lnv-adipo-HO-1 (HFD) mice; $n=5,{ }^{*} p$ $<0.05$ versus WT and Lnv-adipo-HO-1 (HFD).

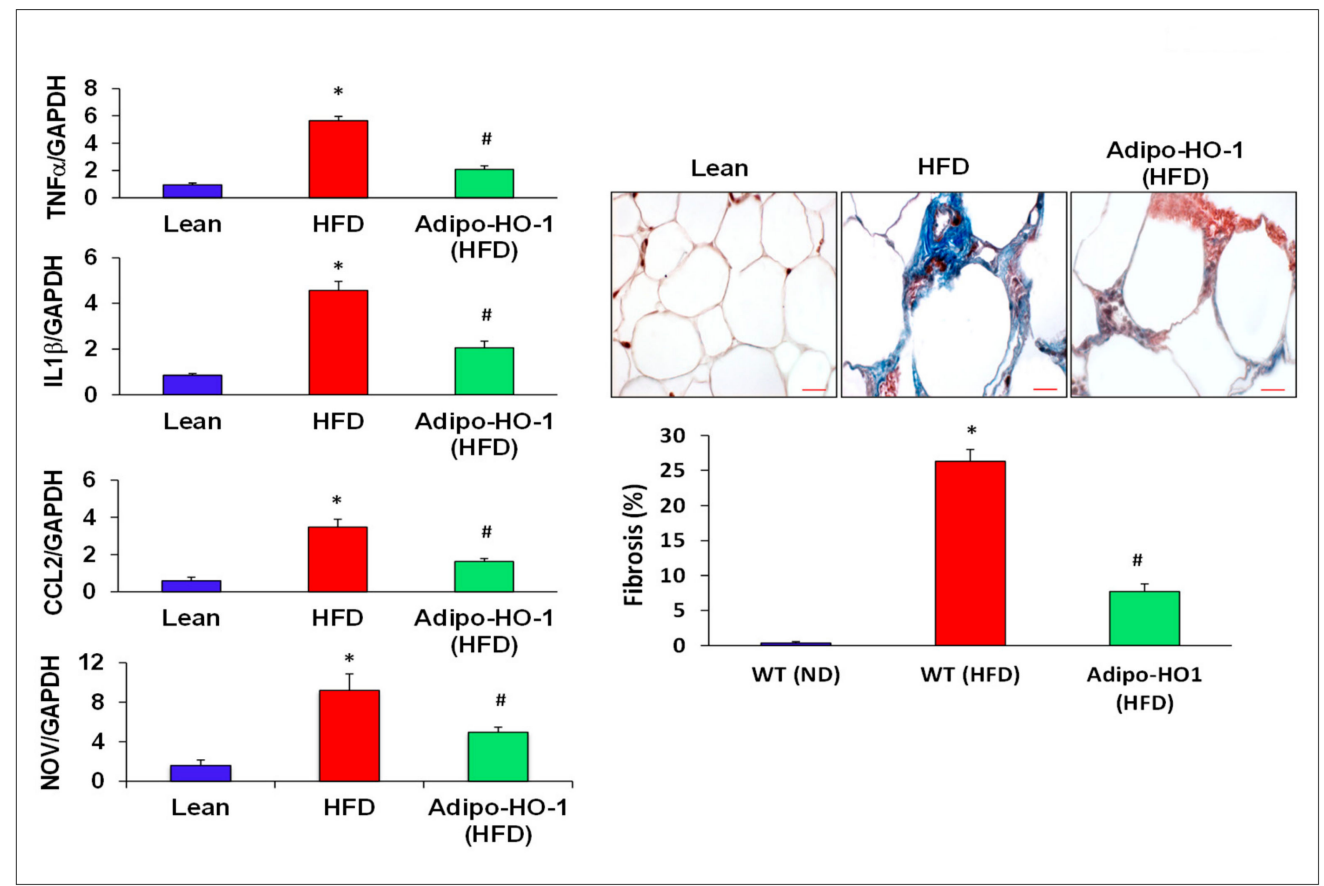

Figure 5. Expression of inflammatory mediators in adipose tissue of lean, HFD, and Lnv-adipo-HO-1 (HFD) mice. Relative mRNA levels of TNF- $\alpha$, IL1 $\beta$, CCL2, and NOV, followed by histological analysis of adipose tissue fibrosis, using hematoxylin/eosin and Masson trichrome staining; $n=5,{ }^{*} p<0.05$ versus lean; $\# p<0.05$ versus HFD alone. 
3.7. Effect of Lnv-adipo-HO-1 Administration on $p A C C, p A K T, p A M P K$, and Insulin Receptor Phosphorylation

An HFD decreased phosphorylation of ACC, AKT, and AMPK protein levels, compared with control lean mice ( $p<0.05$; Figure 6). Transduction by Lnv-adipo-HO-1 normalized the phosphorylation of pACC, pAKT, and pAMPK (Figure 6). Adipose tissue of HFD-fed mice exhibited lower protein levels pIR972 and pIR1146, which was normalized by $\beta$-actin. Lnv-adipo-HO-1 induction produced a significant $(p<0.05)$ increase in protein expression of pIR972 and pIR1146 (Figure 6).

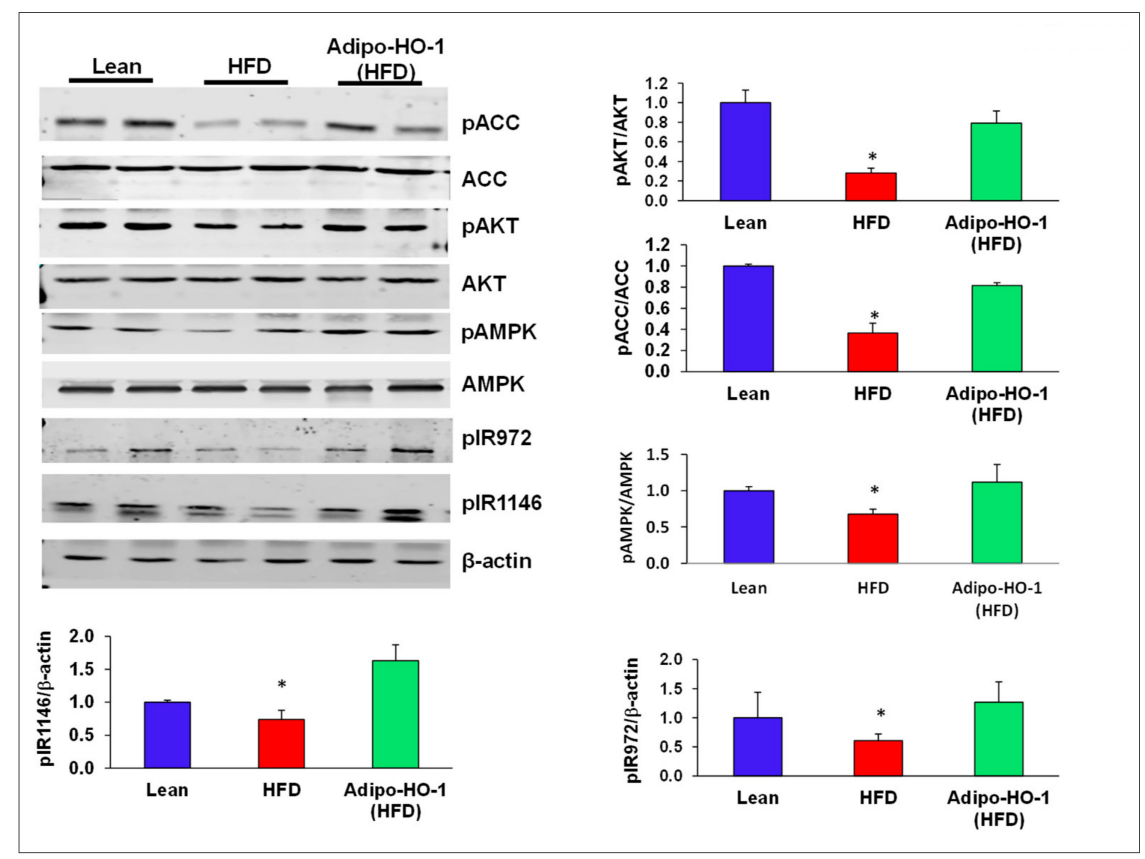

Figure 6. Representative Western blot analysis of insulin receptor phosphorylation and key phosphorylated proteins within the insulin receptor signaling cascade in adipose tissue of lean, HFD, and Lnv-adipo-HO-1 (HFD) mice. Representative Western blots and fluorometric analysis relative to $\beta$-actin of pACC, ACC, pAKT, AKT, pAMPK, AMPK, pIR972, and pIR1146; $n=5$, $p<0.05$ versus lean and Lnv-adipo-HO-1 (HFD) mice.

\subsection{HO-1 Regulation of Mitochondrial Biogenesis, cyp2C44, and Twist1 in Adipocyte Cell Culture}

To further elucidate the central role of HO-1 on mitochondrial function in adipocyte cells, we modified HO-1 levels by both lentivirus-mediated HO-1 downregulation and upregulation in preadipocyte cells in vitro. Whereas knockdown of HO-1 caused a reduction $(p<0.05)$ in the levels of CYP2C44, PGC-1 $\alpha$, MFN1, and MFN2, overexpression of HO-1 caused an increase $(p<0.05)$ in the mRNA levels of these genes, beyond the levels observed in control cells (Figure 7A-F). Conversely, mRNA levels of Fis1 and TWIST1 were increased $(p<0.05)$ in HO-1-deficient cells and reduced $(p<$ 0.05 ) in cells overexpressing $\mathrm{HO}-1$ (Figure $7 \mathrm{~A}-\mathrm{F})$.

\subsection{HO-1 Regulation of Mitochondrial Function in Adipocyte Cell Culture}

To ascertain if the HO-1 KD adipocyte cells show defective mitochondrial bioenergetics, we measured mitochondrial respiration in WT, HO-1 KD, and adipocyte cells overexpressed HO-1. Real-time oxygen-consumption rates (OCRs) in adipocyte cells show that basal respiration, representing the sum of all physiological mitochondrial oxygen consumption, was decreased in the mitochondria from HO-1 deficient cells, indicating lower respiratory function compared with WT cells, which was rescued after overexpression of HO-1 (Figure 7G). The injection of oligomycin led to a decrease in OCR. FCCP was used to generate ATP (Figure 7G) uncouples respiration from oxidative phosphorylation used to measure maximal OCR. HO-1 KD cells showed a lower basal level OCR (Figure 7H), which 
was rescued after overexpression of $\mathrm{HO}-1$ (Figure 7G,I), that displays reduction in the mitochondrial activity. Non-mitochondrial OCR was determined by inhibiting the respiratory chain, using rotenone and antimycin A. ATP turnover was significantly decreased in HO-1-ablated cells (Figure 7I). The maximum respiration was also significantly $(p<0.05)$ lower in $\mathrm{HO}-1$-deficient cells which were rescued after overexpression of $\mathrm{HO}-1$. Mitochondria isolated from $\mathrm{HO}-1$-ablated cells displayed a reduction in coupling efficiency that drives ATP synthesis, which was rescued after overexpression of HO-1 (Figure 7) $(p<0.05)$.
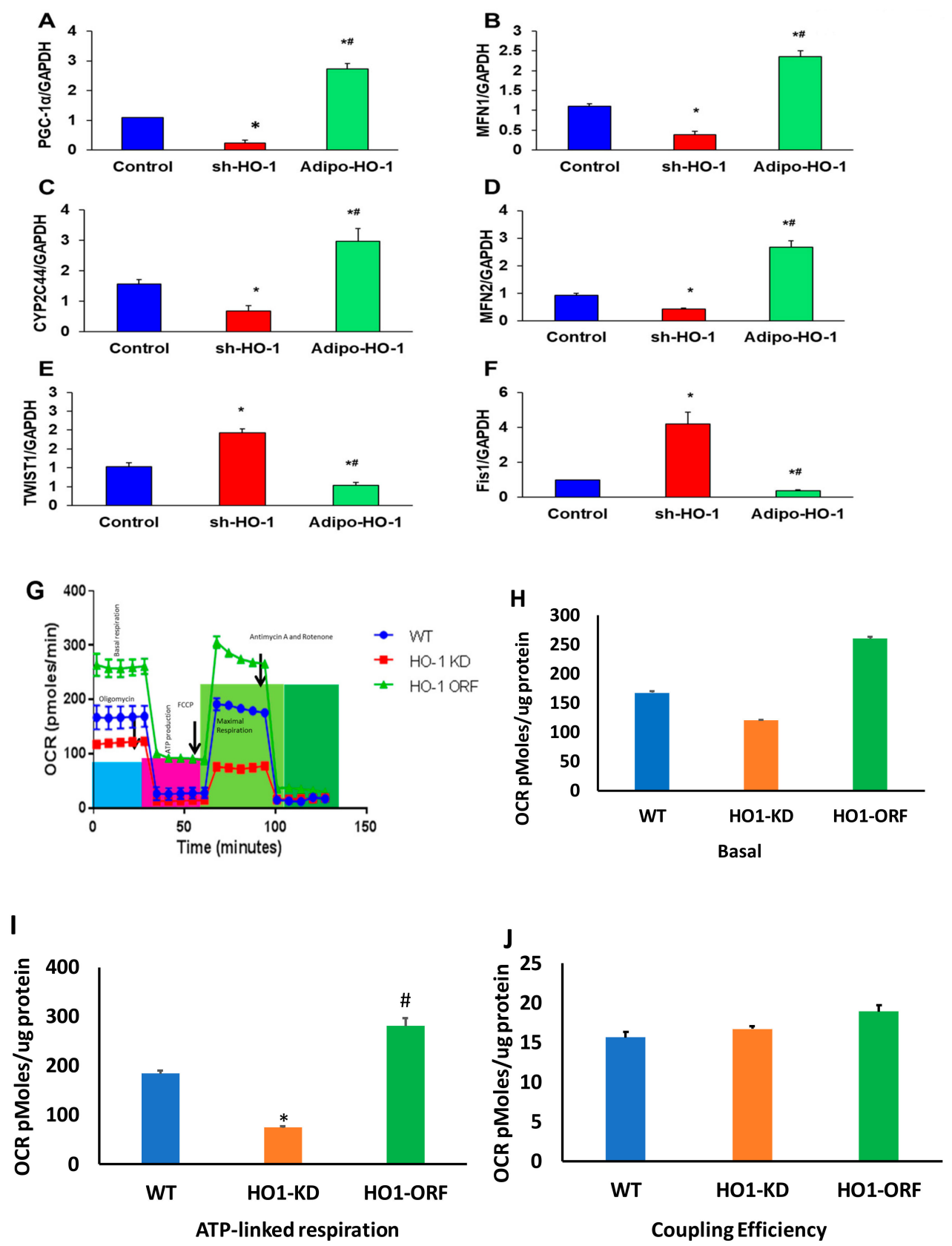

Figure 7. Heme oxygenase-dependent regulation of mitochondrial dynamics and inflammation in vitro. Quantitative gene expression analysis of (A) PGC-1 $\alpha$, (B) MFN1, (C) Cyp2c44, (D) MFN2, (E) Twist1, and (F) Fis1, $n=3,^{*} p<0.05$ versus control; \# $p<0.05$ versus sh-HO-1. (G) HO-1 regulation of mitochondrial function in adipocyte cell culture. (H) Basal of OCR, (I) ATP-linked respiration, and (J) coupling efficiency. Oxygen-consumption rates (OCR) of sh-HO-1 (HO-1 KD), Lnv-adipo-HO-1 (HO-1 ORF), and control cultured adipocytes, $n=3,{ }^{*} p<0.05$ versus control, $\# p<0.05$ vs. HO- 1 KD. 


\subsection{TWIST1 Expression Regulated HO-1 and PGC-1 $\alpha$ in Cultured Adipocyte Cells}

As HO-1 regulated TWIST1 expression levels, we examined whether TWIST1 expression could impact the expression of HO- 1 and its upstream regulating genes, CYP2C44 and PGC- $1 \alpha$. As seen in Figure 8, knockdown of TWIST1 in adipocytes (Figure 8A) caused an upregulation $(p<0.05)$ in the mRNA levels of CYP2C44, PGC-1 $\alpha$ and HO-1 as compared to control cells (Figure 8B-D). Moreover, the real-time oxygen consumption rate in TWIST1-deficient adipocyte cells was elevated, especially the maximal oxygen consumption-rate (after the uncoupling of respiration from oxidative phosphorylation), as compared to control cells (Figure 8E).
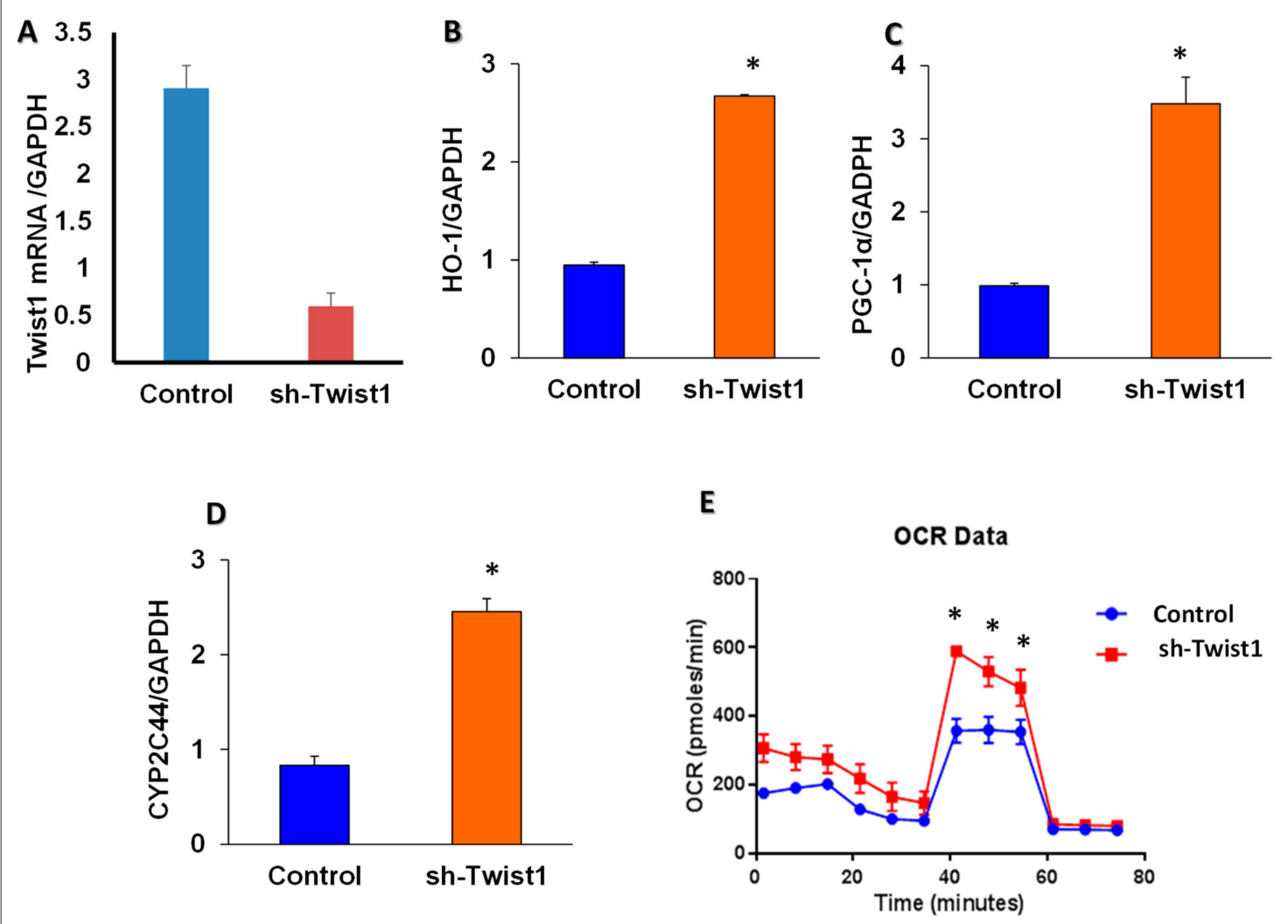

Figure 8. (A) TWIST silencing, effect of TWIST1 silencing on HO-1, PGC-1 $\alpha$, CYP2C44 in cultured adipocyte cells. mRNA expression of (B) HO-1, PGC-1 $\alpha,($ C) and (D) CYP2C44, after shRNA-mediated knockdown of Twist1 and (E) oxygen consumption rates (OCR) of sh-TWIST1 and control cultured adipocytes, $n=3, * p<0.05$ versus control.

3.11. RNA Array Analyses Identify Changes in Correlation Coefficients of Gene Expression in Lean (C), High-Fat (HF), and Heme Oxygenase-1 (HO-1) Lenti-Virus Groups

Our study investigated the role of HO-1 during the adipogenic process and analyzed the expressions of 88 genes that expressed only in adipocytes before and during adipogenesis, as detailed in [6]. The results for the Lnv-adipo-HO-1-injected HFD-fed mice demonstrate marked attenuation of the changes observed in HFD-fed control mice (Figures 9 and 10). Very clearly, the top 10 upregulated genes correlated strongly positively with each other, and the top 10 downregulated genes correlated positively with each other, but very negatively with the other group (Figures 9 and 10). 


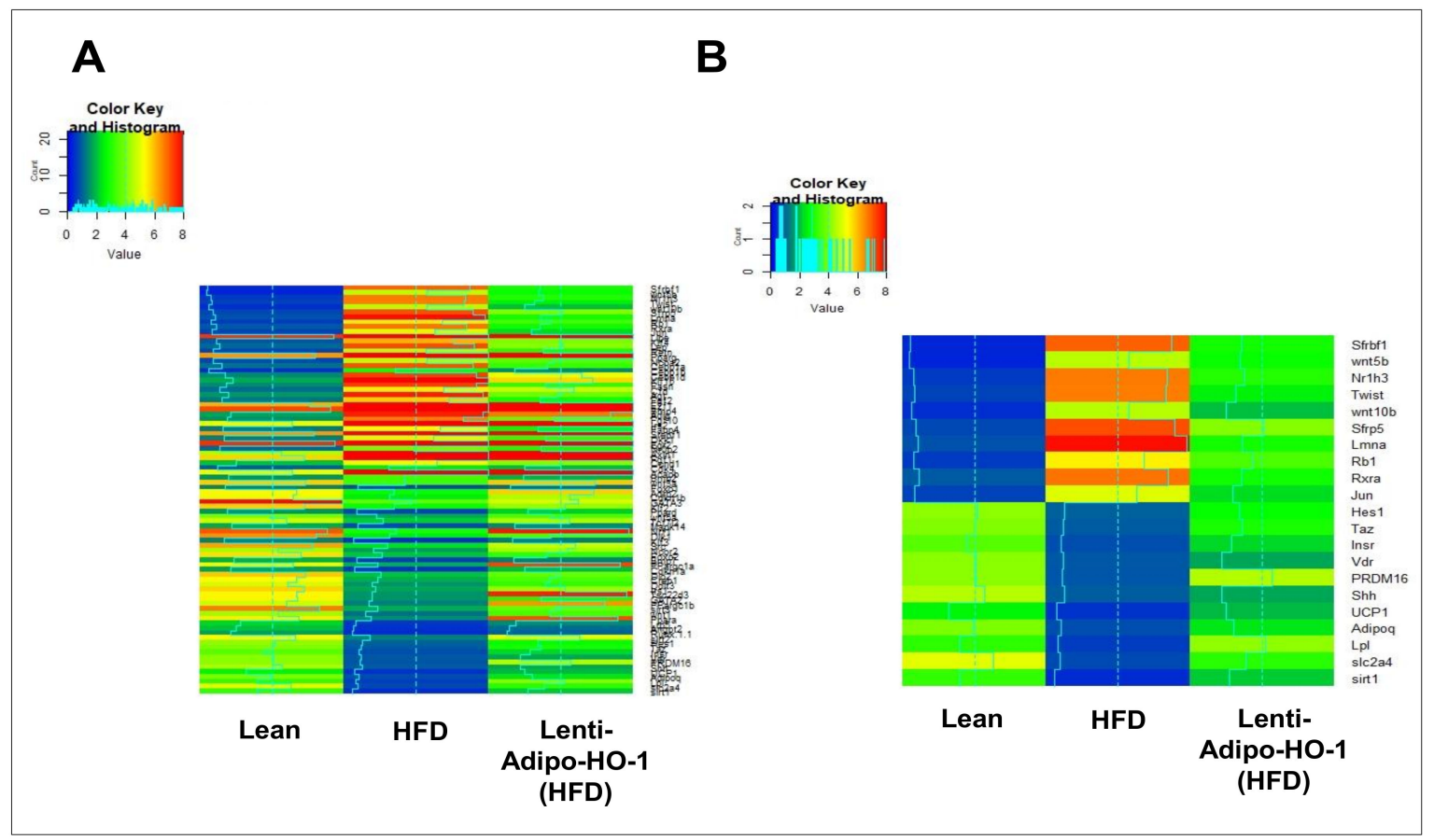

Figure 9. RNA-array-analyses changes in correlation coefficients gene expression in lean, HFD, and Lnv-adipo-HO-1 (HFD) groups. (A) RNA-array-analyses changes in correlation coefficients gene expression of 86 genes involved in Fat Metabolism. (B) RNA array analysis showing changes in correlation coefficients for gene expression of sfrbf1, Wnt5b, Nr1h3, Twist, Wnt10b, Sfrp5, Lmna, Rb1, Rxra, Jun, Hes1, Taz, Insr, Vdr, PRDM16, Shh, UCP1, Adipoq, Lpl, Slc2a4, and Sirt1 in mice injected with Lnv-adipo- HO-1.

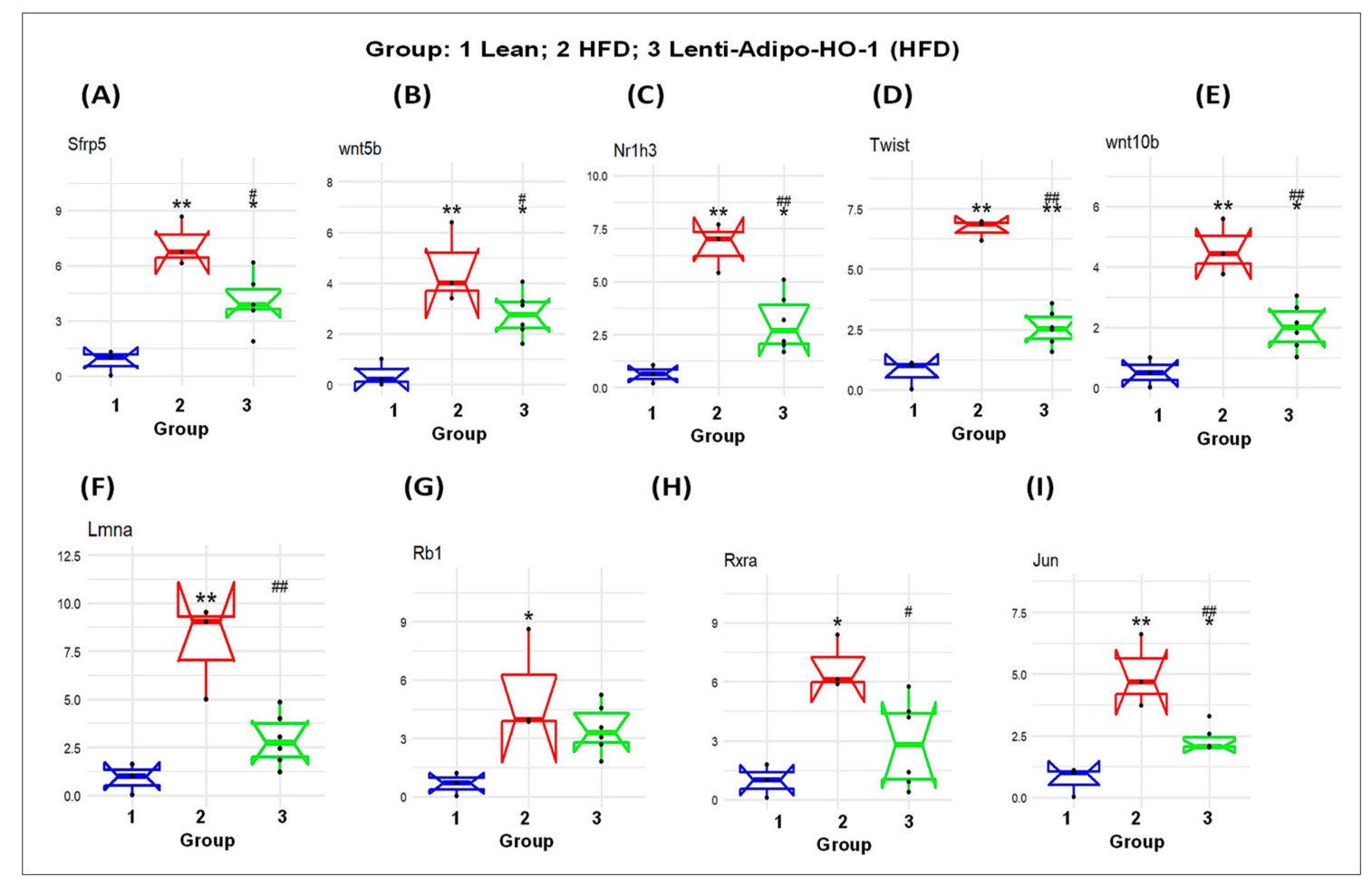

Figure 10. The mRNA expression of lean (Group 1) mice, HFD (Group 2) mice, and Lnv-adipo-HO-1 (HFD) mice (Group 3). (A) sfrp5, (B) wnt5b, (C) Nr1h3, (D) Twist, (E) Wnt10b. (F) Lmna (G) Rb1 (H) Rxra (I) Jun in adipose tissue. $\left(n=5,{ }^{*} p<0.05,{ }^{* *} p<0.005\right.$ vs. lean; $\# p<0.05$, \#\# $p<0.005$ vs. HFD alone). 
3.12. The mRNA Expression Levels as a Result of HO-1 Upregulation in Adipose Tissues of Lean, HFD-Fed, and Lnv-adipo-HO-1-HFD-Fed Mice

As seen in Figure 11, the mRNA levels of Sfrp5, wnt5b, Nr1h3, Twist1, Wnt10b, Lmna, Rb1, Rxra, and Jun were upregulated in adipose tissues of HFD-fed mice, Group 2, as compared to the levels in adipose tissues of lean mice, Group $1\left({ }^{*} p<0.05\right.$ and $\left.{ }^{* *} p<0.005\right)$, and were significantly reduced $\left({ }^{*} p<0.05\right.$ and $\left.{ }^{* *} p<0.005\right)$ in adipose tissues of Lnv-adipo-HO-1-HFD-fed mice as compared to HFD-fed mice, Group 3. Moreover, the mRNA expression levels of some genes, i.e., Sirt1, Slc2a4, Ppard, Adipoq, UCP1, Shh, PRDM16, Lpl, Insr, and Taz were downregulated ${ }^{*} p<0.05$ and $\left.{ }^{* *} p<0.005\right)$ in adipose tissues of HFD-fed mice, Group 2, as compared to the levels in adipose tissues of lean mice, Group 1. As expected, these genes were upregulated $\left({ }^{*} p<0.05\right.$ and $\left.{ }^{* *} p<0.005\right)$ in adipose tissues of Lnv-adipo-HO-1-HFD-fed mice, Group 3, as compared to the mRNA levels in adipose tissues of HFD-fed mice, Group 2 (Figure 11).

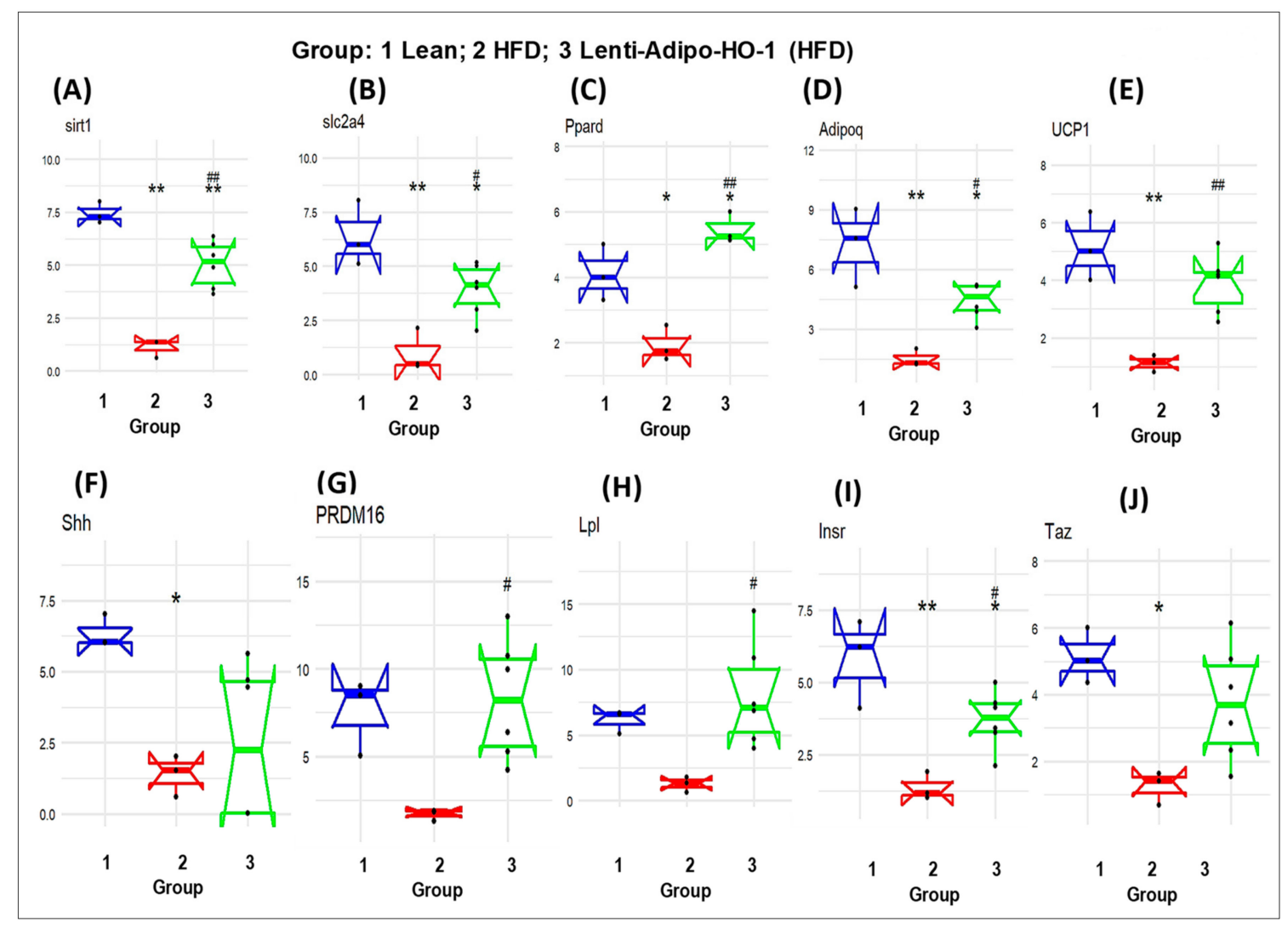

Figure 11. The mRNA expression of (Group 1) mice, HFD (Group 2) mice, and Lnv-adipo-HO-1 (HFD) mice (Group 3). (A) sirt1, (B) slc2a4, (C) Ppard, (D) Adipoq, (E) UCP1, (F) Shh, (G) PRDM16, (H) Lpl, (I) Insr, and (J) Taz. ( $n=5,{ }^{*} p<0.05,{ }^{* *} p<0.005$ vs. lean; $\# p<0.05$, \#\# $p<0.005$ vs. HFD alone).

\section{Discussion}

In the present study, we demonstrate that targeting adipocyte-specific HO-1 gene expression in mice fed an HFD displayed a pronounced metabolic improvement, in spite of food intake being unaltered between the groups. This was manifested by a reduction in body weight and fasting blood glucose levels, and increased glucose tolerance and oxygen consumption. Selective gene targeting of the adipocyte by HO-1 was associated with decreased adipocyte hypertrophy, as measured by a $40 \%$ decrease in adipocyte cell size compared to mice fed an HFD. The Lnv-adipo-HO-1 expression-reduced hypertrophy was associated with decreased levels of the inflammatory molecules, NOV, TWIST, and TNF $\alpha$. Targeted Lnv-adipo-HO-1 expression correlated positively with an improvement in the vasodilatory response to acetylcholine, increased insulin sensitivity, and increased heart mitochondrial 
proteins, suggesting that selective expression of $\mathrm{HO}-1$ in adipocytes has a positive impact in distal organs. An increase of beige-like adipocyte-associated marker genes, energy expenditure, adipocyte respiration in vivo and in adipocyte cell culture, and mitochondrial biogenesis was measured by COX-1 and COX-2. In contrast, knockdown of HO-1 in adipocytes resulted in decreased mitochondrial biogenesis, reduced mitochondrial oxygen consumption, and CYP2C44 levels, but increased levels of pro-inflammatory TWIST1. Finally, RNA microarray and heatmap analysis of adipocyte gene-specific target genes indicate the presence of a protein network that is under control of $\mathrm{HO}-1$ and is depressed in obesity-mediated metabolic dysfunction, which is reversed by the specific targeting of HO-1 in adipocytes.

In this study, we demonstrate that adipocyte-specific HO-1 expression improves adipocyte hypertrophy by decreasing cell size (Figure 1); the progression of obesity is tightly associated with increased adipocyte hypertrophy [24,25,40]. An increase in adipocyte cell size is negatively correlated with adiponectin levels [22]. Further, a reduction of adipocyte hypertrophy is a measure of reprogramming of the white adipocyte phenotype to a beige-like phenotype, which expresses increased levels of mitochondrial, thermogenic, and biogenic genes involved in the stimulation of ATP production and mitochondrial respiration (Figure 9). UCP1 is crucial in maintaining thermogenic pathways that are essential for adipocyte function [41-43]. An increase in HO-1 expression increased expression of carnitine transporter and the ATP/ADP ratio [44]. A decrease in adipocyte carnitine transporter levels impairs thermogenesis and mitochondrial function and increases obesity $[45,46]$. The beiging of white fat is related to decreases in adipose expansion and increased insulin sensitivity that involves increased expression of PRMD16 [47] and of CYP2C44-gene [22,48].

Our findings indicate that the increased expression of HO-1 in adipocytes leads to insulin sensitivity. This is supported by the augmented phosphorylation status of insulin-receptor-associated signaling molecules (ACC, AKT, AMPK, IR p972, and IR p 1146). These data support the concept that adipose tissue releases molecules that benefit distal organs, including the vascular system.

Obesity alone is capable of reducing the $\mathrm{HO}-1$ expression and activity, resulting in insulin resistance in both humans and mice $[6,19]$. As noted above, the direct consequence of the upregulation of HO-1 in adipocytes is an increase in the translocation of PGC- $1 \alpha$ into the adipocyte nucleus, leading to an increased expression of nuclear transcription factors, including mitochondrial genes. PGC-1 $\alpha$ acts as a dominant regulator of mitochondrial biogenesis and thermogenesis by inducing the expression of UCP1 and key enzymes of the mitochondrial respiratory chain [49].

In the current report, specifically targeting adipocytes by HO-1 is associated with a decrease of $\mathrm{NOV}$, a multifunctional protein involved in inflammation and interstitial fibrosis. High levels of NOV have been attributed to obesity, and its ablation reduced inflammation and fat mass and increased insulin sensitivity $[11,38]$. NOV is abundantly expressed in visceral fat, which contributes to vascular dysfunction and a failing heart [11]. Furthermore, ablation of HO-1 in adipocyte cell culture resulted in decreased levels of PGC-1 $\alpha$ and Mfn2, while levels of Fis1 and TWIST increased significantly. Adipocyte-specific HO-1 increased expression resulted in marked reduction in TWIST and Fis1 levels. In addition, oxygen consumption rates (OCR) were increased by ablation of TWIST (Figure 8).

Additionally, we report that CYP2C44 levels were markedly decreased by HO-1 ablation, an effect that was reversed and normalized by increased adipocyte-specific levels of HO- 1 . This is of significance because the reduced expression of CYP2C44 leads to the reduced conversion of arachidonic acid into EETs, a detrimental blow to mitochondrial biogenesis, as EETs promote mitochondrial biogenesis [50].

RNA arrays (88 genes) in adipocytes of visceral fat isolated from HFD-fed Lnv-adipo-HO-1 mice showed a pattern of gene expression that elucidated the mechanisms by which adipocyte HO-1 prevents HFD-driven metabolic dysfunction. Results from Figures 11 and 12 indicated that HO-1 reversed HFD-driven downregulation of SIRT1, LPL, Adiponectin, UCP1, and PRDM16. Thus, our study shows that a set of new genes and biomarkers are an emerging target for the treatment of obesity-mediated metabolic diseases. 


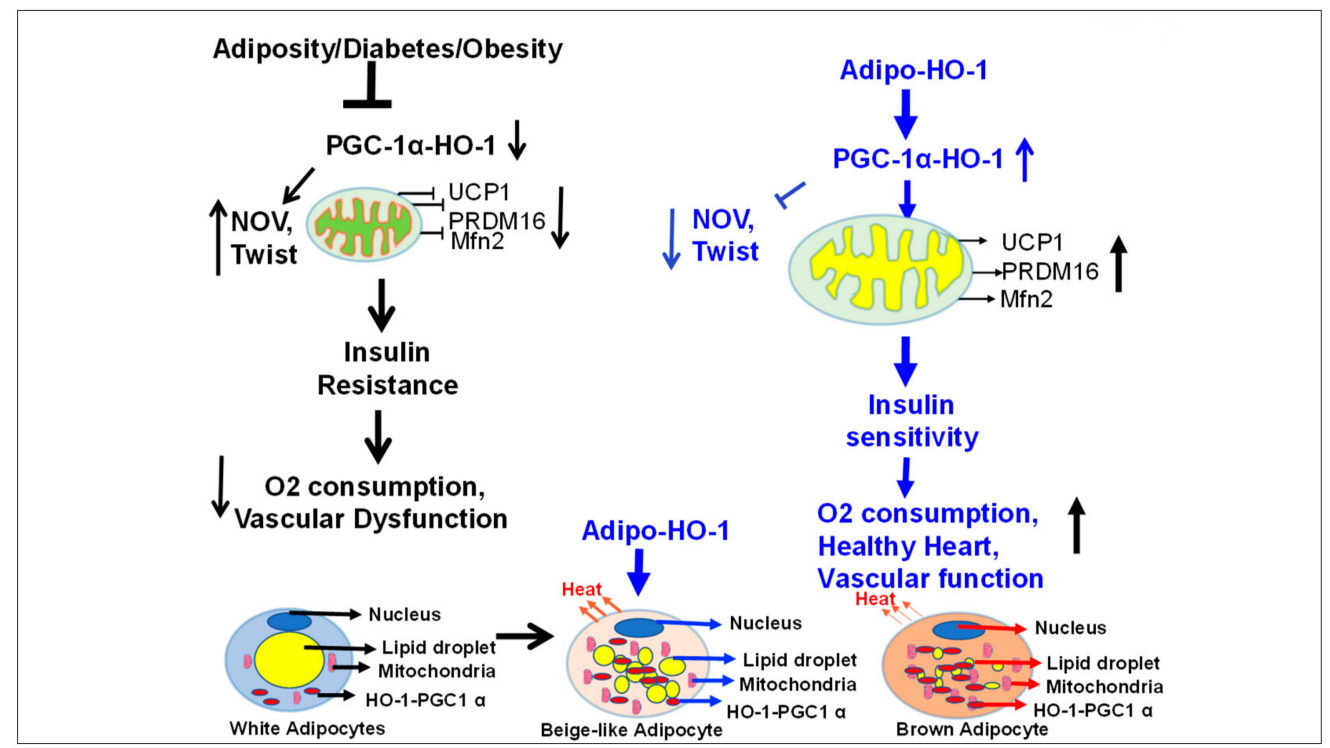

Figure 12. Schematic presentation of postulated mechanisms by which adipocyte-specific HO-1 expression promotes the reprogramming of adipose tissue obese phenotype to a healthy brown-fat phenotype. Obesity leads to a marked suppression of HO-1 within adipocytes, resulting with subsequent increases of inflammatory adipokines, including NOV and TWIST, and leading to suppression of thermogenic genes and mitochondrial dysfunction. These changes at the level of adipocytes are accompanied with reduced energy consumption, impaired vascular function, and insulin resistance. A targeted overexpression of HO-1 within adipocytes prevents and reverses these changes by stimulating PGC1- $\alpha$ expression, leading to an increase in thermogenic genes (UCP1 and PRDM16) and a decrease in inflammatory adipokines, (NOV and TWIST). This, in turn, increases mitochondrial respiration, oxygen consumption, and insulin receptor phosphorylation, all of which contribute to improving vascular function and increasing expression of heart protective genes. Hence, selective expression of adipocyte HO-1 offers a multifactorial clinical approach to the treatment of obesity concomitant metabolic disorders.

\section{Conclusions}

In conclusion, adipocyte-specific expression of HO-1 appears to be a master regulator of adipocyte phenotype and, in turn, is capable of inducing systemic changes in vascular and insulin sensitivity through the action of adipocyte resident signaling pathways (Figure 12). Our results clearly demonstrate that the specific expression of HO-1 in adipocytes has a major impact on distal organs Figure 12. A constellation of findings of HO-1 gene therapy in the obese-mice model clearly demonstrates that targeting adipose tissue with HO-1 gene can drastically influence adipocyte phenotype and reprogram visceral adipocytes to healthy beige-like cells that are capable of anti-inflammatory effects, presumably by promoting the adipocyte release of bioactive molecules that, in turn, impact distal organ function beneficial to reversing the course of metabolic diseases; this process still remains to be elucidated. Lentiviral vectors achieve durable expression of transgene, i.e., HO-1, the increase antioxidants, and reduction of inflammatory adipokines, may have potential for clinical application in humans with HO-1 deficiency.

Author Contributions: Conceptualization, N.G.A.; methodology, S.P.S.; L.B., G.F., and R.R.; software, J.I.S. and L.F.R.; validation, S.P.S. and N.G.A.; formal analysis, J.I.S., S.P.S., M.G., and Y.G.; investigation, N.G.A., J.I.S., and S.P.S.; resources, N.G.A. and J.I.S.; data curation, G.F., R.R., L.F.R., L.B., and K.A.; writing-original draft preparation, S.P.S. and N.G.A.; writing-review and editing, M.G., N.G.A., Y.G., and J.I.S.; visualization, N.G.A., S.P.S., and J.I.S.; supervision, N.G.A.; project administration, N.G.A. and S.P.S.; funding acquisition, N.G.A. All authors had full access to the data and take responsibility for its integrity. All authors have read and agree with the manuscript as written. All authors have read and agreed to the published version of the manuscript. 
Funding: This research was funded by National Institutes of Health grant 1R56HL139561 (N.G.A.). The content is solely the responsibility of the authors and does not necessarily represent the official views of the National Institutes of Health.

Conflicts of Interest: The authors declare that they have no conflicts of interest.

$\begin{array}{ll}\text { Abbreviations } \\ \text { DRP1 } & \text { dynamin-related protein 1 } \\ \text { Fis1 } & \text { mitochondrial fission 1 protein } \\ \text { HFD } & \text { high fat diet } \\ \text { HO-1 } & \text { heme oxygenase-1 } \\ \text { IR } & \text { insulin resistance } \\ \text { MFN 1 } & \text { mitochondrial fusion protein mitofusin 1 } \\ \text { MFN 2 } & \text { mitochondrial fusion protein mitofusin 2 } \\ \text { NOV } & \text { nephroblastoma overexpressed gene } \\ \text { OPA1 } & \text { optic atrophy 1 protein } \\ \text { PGC-1 } \alpha & \text { peroxisome proliferator-activated receptor gamma coactivator } 1-\alpha \\ \text { ROS } & \text { reactive oxygen species } \\ \text { Sirt1 } & \text { sirtuin1 } \\ \text { TWIST1 } & \text { Twist Family BHLH Transcription Factor 1 } \\ \text { UCP1 } & \text { uncoupling protein 1 }\end{array}$

\section{References}

1. Drummond, G.S.; Baum, J.; Greenberg, M.; Lewis, D.; Abraham, N.G. HO-1 Overexpression and Underexpression: Clinical Implications. Arch. Biochem. Biophys. 2019, 673, 108073. [CrossRef] [PubMed]

2. Mitchell, S.; Shaw, D. The worldwide epidemic of female obesity. Best Pract. Res. Clin. Obstet. Gynaecol. 2015, 29, 289-299. [CrossRef] [PubMed]

3. Ladhani, M.; Craig, J.C.; Irving, M.; Clayton, P.A.; Wong, G. Obesity and the risk of cardiovascular and all-cause mortality in chronic kidney disease: A systematic review and meta-analysis. Nephrol. Dial. Transplant. 2017, 32, 439-449. [CrossRef] [PubMed]

4. Lee, B.Y.; Bartsch, S.M.; Mui, Y.; Haidari, L.A.; Spiker, M.L.; Gittelsohn, J. A systems approach to obesity. Nutr. Rev. 2017, 75, 94-106. [CrossRef] [PubMed]

5. Artham, S.M.; Lavie, C.J.; Milani, R.V.; Ventura, H.O. Obesity and hypertension, heart failure, and coronary heart disease-risk factor, paradox, and recommendations for weight loss. Ochsner J. 2009, 9, 124-132. [PubMed]

6. Singh, S.; McClung, J.; Thompson, E.; Glick, Y.; Greenberg, M.; Acosta-Baez, G.; Edris, B.; Shapiro, J.; Abraham, N.G. Cardioprotective heme oxygenase-1-PGC-1 $\alpha$ signaling in epicardial fat attenuates cardiovascular risk in humans as in obese mice. Obesity (Silver Spring) 2019, 27, 1560-1561. [CrossRef]

7. Ellulu, M.S.; Patimah, I.; Khaza'ai, H.; Rahmat, A.; Abed, Y. Obesity and inflammation: The linking mechanism and the complications. Arch. Med. Sci. 2017, 13, 851-863. [CrossRef]

8. Kredel, L.I.; Siegmund, B. Adipose-tissue and intestinal inflammation-visceral obesity and creeping fat. Front. Immunol. 2014, 5, 462. [CrossRef]

9. Fontana, L.; Eagon, J.C.; Trujillo, M.E.; Scherer, P.E.; Klein, S. Visceral fat adipokine secretion is associated with systemic inflammation in obese humans. Diabetes 2007, 56, 1010-1013. [CrossRef]

10. Singh, S.P.; Bellner, L.; Vanella, L.; Cao, J.; Falck, J.R.; Kappas, A.; Abraham, N.G. Downregulation of PGC-1alpha Prevents the Beneficial Effect of EET-Heme Oxygenase-1 on Mitochondrial Integrity and Associated Metabolic Function in Obese Mice. J. Nutr. Metab. 2016, 2016, 9039754. [CrossRef]

11. Singh, S.P.; McClung, J.A.; Bellner, L.; Cao, J.; Waldman, M.; Schragenheim, J.; Arad, M.; Hochhauser, E.; Falck, J.R.; Weingarten, J.A.; et al. CYP-450 Epoxygenase Derived Epoxyeicosatrienoic Acid Contribute To Reversal of Heart Failure in Obesity-Induced Diabetic Cardiomyopathy via PGC-1 alpha Activation. Cardiovasc. Pharmacol. Open Access 2018, 7, 233. [CrossRef] 
12. Singh, S.P.; Schragenheim, J.; Cao, J.; Falck, J.R.; Abraham, N.G.; Bellner, L. PGC-1 alpha regulates HO-1 expression, mitochondrial dynamics and biogenesis: Role of epoxyeicosatrienoic acid. Prostaglandins Other Lipid Mediat. 2016, 125, 8-18. [CrossRef] [PubMed]

13. Pucci, G.; Battista, F.; De Vuono, S.; Boni, M.; Scavizzi, M.; Ricci, M.A.; Lupattelli, G.; Schillaci, G. Pericardial fat, insulin resistance, and left ventricular structure and function in morbid obesity. Nutr. Metab. Cardiovasc. Dis. 2014, 24, 440-446. [CrossRef] [PubMed]

14. Kawashima, A.; Oda, Y.; Yachie, A.; Koizumi, S.; Nakanishi, I. Heme oxygenase-1 deficiency: The first autopsy case. Hum. Pathol. 2002, 33, 125-130. [CrossRef] [PubMed]

15. Kartikasari, A.E.; Wagener, F.A.; Yachie, A.; Wiegerinck, E.T.; Kemna, E.H.; Swinkels, D.W. Hepcidin suppression and defective iron recycling account for dysregulation of iron homeostasis in heme oxygenase-1 deficiency. J. Cell. Mol. Med. 2009, 13, 3091-3102. [CrossRef] [PubMed]

16. Ohta, K.; Yachie, A.; Fujimoto, K.; Kaneda, H.; Wada, T.; Toma, T.; Seno, A.; Kasahara, Y.; Yokoyama, H.; Seki, H.; et al. Tubular injury as a cardinal pathologic feature in human heme oxygenase-1 deficiency. Am. J. Kidney Dis. 2000, 35, 863-870. [CrossRef]

17. Poss, K.D.; Tonegawa, S. Heme oxygenase 1 is required for mammalian iron reutilization. Proc. Natl. Acad. Sci. USA 1997, 94, 10919-10924. [CrossRef]

18. Poss, K.D.; Tonegawa, S. Reduced stress defense in heme oxygenase 1-deficient cells. Proc. Natl. Acad. Sci. USA 1997, 94, 10925-10930. [CrossRef]

19. Shakeri-Manesch, S.; Zeyda, M.; Huber, J.; Ludvik, B.; Prager, G.; Stulnig, T.M. Diminished upregulation of visceral adipose heme oxygenase-1 correlates with waist-to-hip ratio and insulin resistance. Int. J. Obes. Lond 2009, 33, 1257-1264. [CrossRef]

20. Hosick, P.A.; Weeks, M.F.; Hankins, M.W.; Moore, K.H.; Stec, D.E. Sex-Dependent Effects of HO-1 Deletion from Adipocytes in Mice. Int. J. Mol. Sci. 2017, 18, 611. [CrossRef]

21. Cao, J.; Singh, S.P.; McClung, J.; Joseph, G.; Vanella, L.; Barbagallo, I.; Jiang, H.; Falck, J.R.; Arad, M.; Shapiro, J.I.; et al. EET Intervention on Wnt1, NOV and HO-1 Signaling Prevents Obesity-Induced Cardiomyopathy in Obese Mice. Am. J. Physiol. Heart Circ. Physiol. 2017, 313, H368-H380. [CrossRef]

22. Abraham, N.G.; Sodhi, K.; Silvis, A.M.; Vanella, L.; Favero, G.; Rezzani, R.; Lee, C.; Zeldin, D.C.; Schwartzman, M.L. CYP2J2 targeting to endothelial cells attenuates adiposity and vascular dysfunction in mice fed a high-fat diet by reprogramming adipocyte phenotype. Hypertension 2014, 64, 1352-1361. [CrossRef]

23. Vanella, L.; Sodhi, K.; Kim, D.H.; Puri, N.; Maheshwari, M.; Hinds, T.D., Jr.; Bellner, L.; Goldstein, D.; Peterson, S.J.; Shapiro, J.I.; et al. Increased heme-oxygenase 1 expression decreases adipocyte differentiation and lipid accumulation in mesenchymal stem cells via upregulation of the canonical Wnt signaling cascade. Stem Cell Res. Ther. 2013, 4, 28. [CrossRef] [PubMed]

24. Nicolai, A.; Li, M.; Kim, D.H.; Peterson, S.J.; Vanella, L.; Positano, V.; Gastaldelli, A.; Rezzani, R.; Rodella, L.F.; Drummond, G.; et al. Heme oxygenase-1 induction remodels adipose tissue and improves insulin sensitivity in obesity-induced diabetic rats. Hypertension 2009, 53, 508-515. [CrossRef] [PubMed]

25. Peterson, S.J.; Rubinstein, R.; Faroqui, M.; Raza, A.; Boumaza, I.; Zhang, Y.; Stec, D.; Abraham, N.G. Positive Effects of Heme Oxygenase Upregulation on Adiposity and Vascular Dysfunction: Gene Targeting vs. Pharmacologic Therapy. Int. J. Mol. Sci. 2019, 20, 2514. [CrossRef]

26. Sacerdoti, D.; Singh, S.P.; Schragenheim, J.; Bellner, L.; Vanella, L.; Raffaele, M.; Meissner, A.; Grant, I.; Favero, G.; Rezzani, R.; et al. Development of NASH in Obese Mice is Confounded by Adipose Tissue Increase in Inflammatory NOV and Oxidative Stress. Int. J. Hepatol. 2018, 2018, 3484107. [CrossRef]

27. Abraham, N.G.; Kappas, A. Pharmacological and clinical aspects of heme oxygenase. Pharmacol. Rev. 2008, 60, 79-127. [CrossRef] [PubMed]

28. Abraham, N.G.; Junge, J.M.; Drummond, G.S. Translational Significance of Heme Oxygenase in Obesity and Metabolic Syndrome. Trends Pharmacol. Sci. 2016, 37, 17-36. [CrossRef] [PubMed]

29. Drummond, H.A.; Mitchell, Z.L.; Abraham, N.G.; Stec, D.E. Targeting Heme Oxygenase-1 in Cardiovascular and Kidney Disease. Antioxidants 2019, 8, 181. [CrossRef]

30. Cao, J.; Peterson, S.J.; Sodhi, K.; Vanella, L.; Barbagallo, I.; Rodella, L.F.; Schwartzman, M.L.; Abraham, N.G.; Kappas, A. Heme oxygenase gene targeting to adipocytes attenuates adiposity and vascular dysfunction in mice fed a high-fat diet. Hypertension 2012, 60, 467-475. [CrossRef] 
31. Schreyer, S.A.; Wilson, D.L.; LeBoeuf, R.C. C57BL/6 mice fed high fat diets as models for diabetes-accelerated atherosclerosis. Atherosclerosis 1998, 136, 17-24. [CrossRef]

32. Surwit, R.S.; Kuhn, C.M.; Cochrane, C.; McCubbin, J.A.; Feinglos, M.N. Diet-induced type II diabetes in C57BL/6J mice. Diabetes 1988, 37, 1163-1167. [CrossRef] [PubMed]

33. Sabaawy, H.E.; Zhang, F.; Nguyen, X.; Elhosseiny, A.; Nasjletti, A.; Schwartzman, M.; Dennery, P.; Kappas, A.; Abraham, N.G. Human heme oxygenase-1 gene transfer lowers blood pressure and promotes growth in spontaneously hypertensive rats. Hypertension 2001, 38, 210-215. [CrossRef] [PubMed]

34. Waldman, M.; Bellner, L.; Vanella, L.; Schragenheim, J.; Sodhi, K.; Singh, S.P.; Lin, D.; Lakhkar, A.; Li, J.; Hochhauser, E.; et al. Epoxyeicosatrienoic Acids Regulate Adipocyte Differentiation of Mouse 3T3 Cells, Via PGC-1alpha Activation, Which Is Required for HO-1 Expression and Increased Mitochondrial Function. Stem Cells Dev. 2016, 25, 1084-1094. [CrossRef]

35. Olszanecki, R.; Rezzani, R.; Omura, S.; Stec, D.E.; Rodella, L.; Botros, F.T.; Goodman, A.I.; Drummond, G.; Abraham, N.G. Genetic suppression of HO-1 exacerbates renal damage: Reversed by an increase in the antiapoptotic signaling pathway. Am. J. Physiol. Renal. Physiol. 2007, 292, F148-F157. [CrossRef]

36. Abraham, N.G.; Kushida, T.; McClung, J.; Weiss, M.; Quan, S.; Lafaro, R.; Darzynkiewicz, Z.; Wolin, M. Heme oxygenase-1 attenuates glucose-mediated cell growth arrest and apoptosis in human microvessel endothelial cells. Circ. Res. 2003, 93, 507-514. [CrossRef]

37. Warnes, G.R.; Bolker, B.; Bonebakker, L.; Gentleman, R.; Liaw, W.H.A.; Lumley, T.; Maechler, M.; Magnusson, A.; Moeller, S.; Schwartz, M.; et al. Gplots: Various R Programming Tools for Plotting Data. R Package Version 3.0.1.1. 2019. Available online: https:/CRAN.R-project.org/package=gplots (accessed on 31 December 2019).

38. Schragenheim, J.; Bellner, L.; Cao, J.; Singh, S.P.; Bamshad, D.; McClung, J.A.; Maayan, O.; Meissner, A.; Grant, I.; Stier, C.T., Jr.; et al. EET enhances renal function in obese mice resulting in restoration of HO-1-Mfn1/2 signaling, and decrease in hypertension through inhibition of sodium chloride co-transporter. Prostaglandins Other Lipid Mediat. 2018, 137, 30-39. [CrossRef]

39. Kaide, J.-I.; Zhang, F.; Wei, Y.; Jiang, H.; Yu, C.; Wang, W.H.; Balazy, M.; Abraham, N.G.; Nasjletti, A. Carbon monoxide of vascular origin attenuates the sensitivity of renal arterial vessels to vasoconstrictors. J. Clin. Investig. 2001, 107, 1163-1171. [CrossRef]

40. Burgess, A.; Li, M.; Vanella, L.; Kim, D.H.; Rezzani, R.; Rodella, L.; Sodhi, K.; Canestraro, M.; Martasek, P.; Peterson, S.J.; et al. Adipocyte heme oxygenase-1 induction attenuates metabolic syndrome in both male and female obese mice. Hypertension 2010, 56, 1124-1130. [CrossRef]

41. Chouchani, E.T.; Kazak, L.; Spiegelman, B.M. New Advances in Adaptive Thermogenesis: UCP1 and Beyond. Cell Metab. 2019, 29, 27-37. [CrossRef]

42. Cohen, P.; Spiegelman, B.M. Brown and Beige Fat: Molecular Parts of a Thermogenic Machine. Diabetes 2015, 64, 2346-2351. [CrossRef] [PubMed]

43. Gupta, R.K.; Rosen, E.D.; Spiegelman, B.M. Identifying novel transcriptional components controlling energy metabolism. Cell Metab. 2011, 14, 739-745. [CrossRef] [PubMed]

44. Di Noia, M.A.; Van, D.S.; Palmieri, F.; Yang, L.M.; Quan, S.; Goodman, A.I.; Abraham, N.G. Heme oxygenase-1 enhances renal mitochondrial transport carriers and cytochrome $\mathrm{C}$ oxidase activity in experimental diabetes. J. Biol. Chem. 2006, 281, 15687-15693. [CrossRef] [PubMed]

45. Bertholet, A.M.; Chouchani, E.T.; Kazak, L.; Angelin, A.; Fedorenko, A.; Long, J.Z.; Vidoni, S.; Garrity, R.; Cho, J.; Terada, N.; et al. $\mathrm{H}(+)$ transport is an integral function of the mitochondrial ADP/ATP carrier. Nature 2019, 571, 515-520. [CrossRef] [PubMed]

46. Lee, H.H.; An, S.M.; Ye, B.J.; Lee, J.H.; Yoo, E.J.; Jeong, G.W.; Kang, H.J.; Alfadda, A.A.; Lim, S.W.; Park, J.; et al. TonEBP/NFAT5 promotes obesity and insulin resistance by epigenetic suppression of white adipose tissue beiging. Nat. Commun. 2019, 10, 3536. [CrossRef] [PubMed]

47. Cohen, P.; Levy, J.D.; Zhang, Y.; Frontini, A.; Kolodin, D.P.; Svensson, K.J.; Lo, J.C.; Zeng, X.; Ye, L.; Khandekar, M.J.; et al. Ablation of PRDM16 and beige adipose causes metabolic dysfunction and a subcutaneous to visceral fat switch. Cell 2014, 156, 304-316. [CrossRef] [PubMed]

48. Liu, L.; Puri, N.; Raffaele, M.; Schragenheim, J.; Singh, S.P.; Bradbury, J.A.; Bellner, L.; Vanella, L.; Zeldin, D.C.; Cao, J.; et al. Ablation of soluble epoxide hydrolase reprogram white fat to beige-like fat through an increase in mitochondrial integrity, HO-1-adiponectin in vitro and in vivo. Prostaglandins Other Lipid Mediat. 2018, 138, 1-8. [CrossRef] 
49. Wu, J.; Cohen, P.; Spiegelman, B.M. Adaptive thermogenesis in adipocytes: Is beige the new brown? Genes Dev. 2013, 27, 234-250. [CrossRef]

50. Wang, L.; Chen, M.; Yuan, L.; Xiang, Y.; Zheng, R.; Zhu, S. 14,15-EET promotes mitochondrial biogenesis and protects cortical neurons against oxygen/glucose deprivation-induced apoptosis. Biochem. Biophys. Res. Commun. 2014, 450, 604-609. [CrossRef] 